\title{
Analysis and Optimization of Driving Attitude and Oscillation Characteristics of Suspension-Type Small Rail Vehicles
}

\author{
Bing Liu, Huijun Yue $\mathbb{D}$, Jiachun Lin, Xiangkai Wu, and Zhaoyao Shi \\ College of Mechanical Engineering and Applied Electronics Technology, Beijing University of Technology, Beijing 100124, China \\ Correspondence should be addressed to Huijun Yue; yuehj@bjut.edu.cn
}

Received 16 August 2020; Revised 31 October 2020; Accepted 12 November 2020; Published 4 December 2020

Academic Editor: Abdollah Malekjafarian

Copyright (c 2020 Bing Liu et al. This is an open access article distributed under the Creative Commons Attribution License, which permits unrestricted use, distribution, and reproduction in any medium, provided the original work is properly cited.

\begin{abstract}
Suspension-type small rail personal rapid transit systems are widely concerned due to their high efficiency and reliability. The increasing demands for ride comfort have put forward higher requirements for vehicle stationarity. In the study, with a singlebogie vehicle as the research object, a dynamic equation and a simulation model are firstly established to calculate the attitude angle and lateral velocity of the vehicle. Then, with the small amplitude and fast attenuation of the attitude angle and lateral velocity in a straight line and a bend as optimization objectives, the simulation model is optimized in terms of a series of variables, including the bogie with or without the supporting wheel, the supporting wheel tread, the driving wheel tread, the guide wheel tread, and the changes of the center of mass of the vehicle. Then, the problem of severe vehicle pitch with the double-bogie structure is solved. Finally, the simulation results and the optimization scheme are experimentally verified. The above optimization measures can significantly improve the driving stationarity of suspension-type small rail vehicles and enhance ride comfort.
\end{abstract}

\section{Introduction}

Traffic congestion is a problem that currently plagues urban development [1]. In order to meet the travel demand of the modern society and improve the convenience and comfort of transportation, personal rapid transit (PRT) has been proposed [2, 3]. In 1953, Donn Fichter defined the PRT system as an automated urban transportation system composed of small vehicles and light rails $[4,5]$. With the increase in the requirements for the traffic landscape, the PRT system with suspension-type small rail vehicles has attracted wide attention. The low-altitude suspended bridgerail system using ultralight rails is characterized by the rail network layout and low construction cost [6-8]. Transport vehicle has become a dynamic urban landscape. In order to further improve its ride experience, it is necessary to further explore the driving attitude and oscillation characteristics of such vehicles [9].

Cai et al. established a coupled dynamic model and a finite element model for the suspended monorail system based on the multibody dynamics and finite element method and explored the coupling relationship between the vehicle and the bridge of the suspended monorail system through theoretical analysis and simulation [10]. Bao et al. conducted a detailed numerical study on the safety of the suspended monorail vehicles and the dynamic characteristics of the bridge structure, evaluated the safety and reliability of the suspended monorail system, and indicated that the dynamic response of the bridge caused by the short train group was small [11]. Kozłowski et al. established a full-size dynamic simulation model of a suspension-type PRT system vehicle, verified the model with a physical model $(1: 4)$, and pointed out that the design parameters of the vehicle should be optimized in order to reduce the vibration and slip of the vehicle passing through a bend [12]. Jiang et al. proposed a dynamic optimization model of articulated monorail vehicles based on the genetic algorithm, optimized the suspension parameters of monorail vehicles, and improved the ride comfort [13]. He et al. established an improved trainbridge interaction model, investigated the dynamic performance of the suspended monorail vehicle on the circle curve bridge, and found that the rational allocation of shock 
absorbers could effectively suppress the vibration of the vehicle [14]. Gao et al. established a coupled vehicle-bridge model of the straddle-type monorail based on multibody dynamics and the finite element method and studied the influences of vehicle speed, pier height, track irregularity, and vehicle load on ride comfort [15]. Taking the straddletype monorail as the research object, Junchao et al. established a dynamic model of vehicles and the tire-track contact model to analyze the influences of different velocities and tire stiffness on vibration characteristics of vehicles [16]. In order to evaluate the dynamic behaviours of the straddletype monorail vehicle with bogies accurately, Zhou et al. proposed the full-scale rigid-flexible coupling multibody dynamic model based on multibody dynamics and finite element theory and studied the influences of vehicle velocity and curve radius on dynamic characteristics [17]. Gou et al. investigated and experimentally verified the dynamic behaviours of the bridge under moving straddle-type monorail trains, evaluated the ride comfort of trains, and indicated that vehicle velocity was the dominant factor influencing the ride comfort of trains [18]. Wang and Zhu carried out the dynamic response analysis of the monorail steel-concrete composite beam-train interaction system based on the consideration of the slip effect [19]. Naeimi et al. studied the dynamic interaction of the monorail-bridge system with a combined finite element-multibody-based model and analyzed dynamic responses of the vehicles and bridges under different loading conditions for the purpose of guiding the structural design of bridges [20].

Previous studies on the driving stationarity and comfort of suspension-type rail vehicles mainly focus on medium and large rails and vehicles, which are characterized by large and complex bogies and carriages, large turning radius, long starting and braking time, and the low requirements of ride comfort. Without a track change device, such vehicles generally realize track change and turning by moving switches. The inherent characteristics of the bridge and vehicle vibration have been studied, but the attitude change during vehicle driving was still obscure.

The research object of this paper is the novel small rail transit system. The novel system combines the advantages of rail transit vehicles and automobiles and is characterized by simple structure, small turning radius, short starting and braking time, and flexible manoeuvring. The ride comfort of such vehicles is comparable to that of automobiles. The vehicles turn through their own steering arm without requiring moving the switch. Although the research object in this study is rail vehicles, the analysis methods and standards of automobiles are also applicable to the study. The study aims to analyze and optimize the driving attitude of such vehicles. Therefore, the study on this novel small rail transit system is of significant theoretical and engineering values.

In this paper, based on two evaluation indicators of vehicles (the attitude angle and lateral velocity), a 3-DOF theoretical model considering the roll of carriage is established with the Lagrange method, and the dynamic equation of a single-bogie suspension-type small rail vehicle is derived. Then, with the multibody dynamics simulation platform, a simulation model of the single-bogie vehicle is established, and the changes of attitude angle and lateral velocity of the vehicle traveling in a straight line and a bend are obtained. The influences of the design parameters on stationarity are explored by the sensitivity analysis. With the small amplitude and fast attenuation of the attitude angle and lateral velocity as the optimization objective, the optimal design parameters within the size constraint ranges are obtained through scheme optimization to obtain the optimized model. Finally, the experimental data are compared with the simulation results to verify the accuracy and validity of the simulation model.

\section{Theoretical Analysis of Dynamics of the Suspension-Type Small Rail Vehicle}

The suspension-type small rail vehicle is composed of four parts: the overall bogie, the carriage, electrical equipment, and auxiliary equipment, as shown in Figure 1. Different from the vehicle bogie structure used in traditional rail transit systems, a bogie structure similar to the chassis of a car on the road is adopted in the system. The similar bogie structure adopts rubber tires with the cushioning effect and is driven by the proper hub motor, which is integrated with the disc brake to ensure the sufficient braking force. Unlike the chassis, vehicle steering depends on the cooperation of the steering mechanism and the track structure.

2.1. Kinetic Equation. The Lagrange method is used to establish the dynamic model of the suspension-type small rail vehicle. The established model is a 3 -DOF model considering the roll of the vehicle. In this model, with the core of the roll angle, the vehicle is divided into the bogie part and the carriage part with a roll DOF. The model is similar to the model considering yaw and pitch [21-23]. The theoretical model is based on the following simplified assumptions:

(1) The influence of the track flatness in the vertical direction is ignored

(2) The air resistance is ignored

(3) The vehicle is only subjected to minor disturbances in the vicinity of a balanced state

(4) In the theoretical analysis, the degree of freedom of the carriage's rolling direction relative to the bogie is released to improve the adaptability of the theoretical model to different connection structures

(5) In the theoretical analysis, the front two wheels and the auxiliary structure of the bogie are simplified as the front axle, and the rear two wheels and the auxiliary structure are simplified as the rear axle

The bogie of a suspension-type small rail vehicle is similar to the chassis of a car, but it runs on an extremely flat steel track, which generates only a small excitation. In addition, the driving system uses rubber tires with the cushioning effect. Therefore, the influence of the track on the vehicle in the vertical direction can be ignored. The natural frequencies of the system are given in Table 1 . The stiffness values of driving wheels, guide wheels, and supporting 


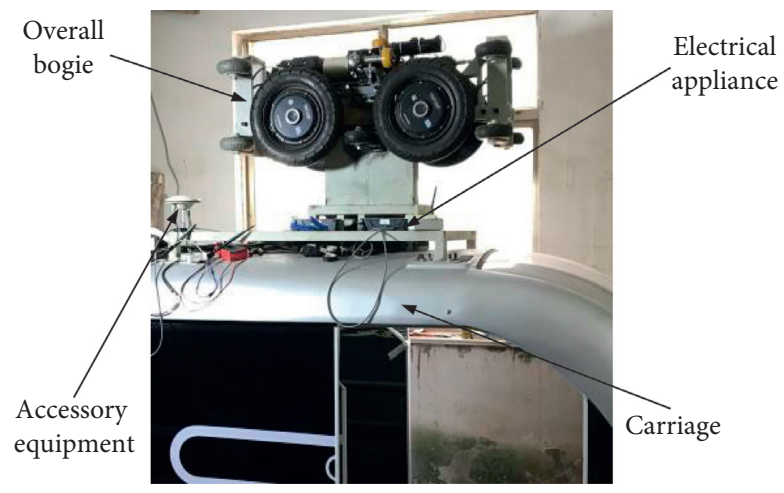

(a)

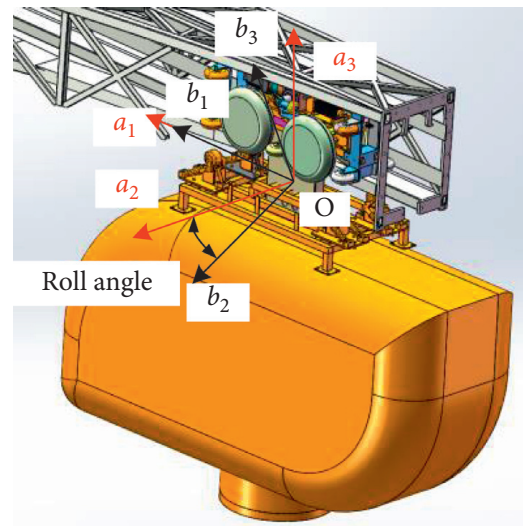

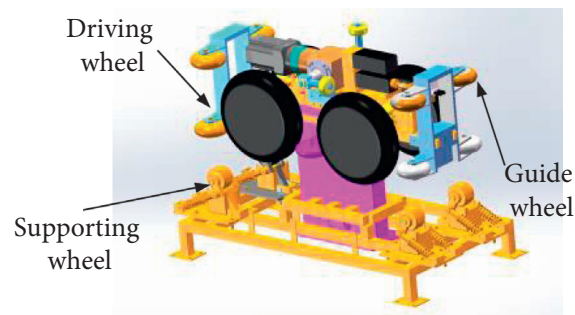

(b)
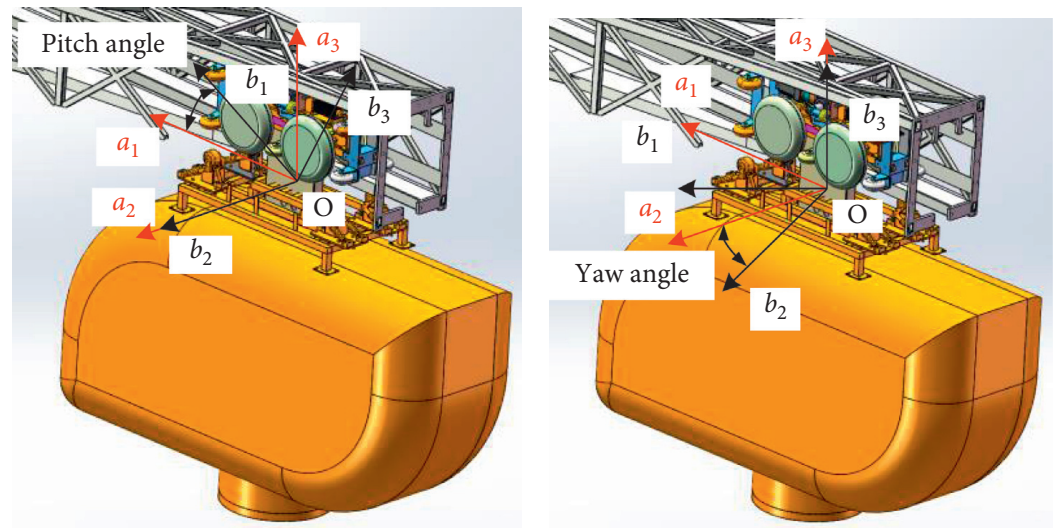

(c)

Figure 1: Structures of the (a) vehicle and (b) bogie as well as (c) attitude angle.

TABle 1: Natural frequencies of the system.

\begin{tabular}{lcc}
\hline Orders & Frequencies $(\mathrm{Hz})$ & Modes \\
\hline 1 & 0.34 & Pitching motion of the carriage \\
2 & 0.48 & Rolling motion of the carriage \\
3 & 0.57 & Yawing motion of the carriage \\
4 & 3.79 & Pitching motion of the bogie \\
5 & 6.58 & Yawing motion of the bogie \\
6 & 8.17 & Yawing motion of the bogie mounting rack \\
7 & 9.91 & Pitching motion of the bogie mounting rack \\
8 & 12.14 & Rolling motion of the bogie \\
9 & 17.67 & Rolling motion of the bogie mounting rack \\
10 & 32.96 & Lateral bending vibration of the bogie \\
11 & 36.97 & Bending vibration of the bogie rear axle \\
12 & 38.47 & Twisting vibration of the bogie \\
13 & 42.80 & Twisting vibration of the bogie rear axle \\
14 & 46.06 & Lateral bending vibration of the bogie \\
15 & 52.59 & Bending vibration of the bogie front axle \\
16 & 63.91 & Twisting vibration of the bogie mounting rack \\
17 & 80.27 & Lateral bending vibration of bogie boom \\
18 & 84.92 & Vertical bending vibration of the bogie mounting rack \\
\hline
\end{tabular}

wheels are $50,000 \mathrm{~N} / \mathrm{m}, 70,000 \mathrm{~N} / \mathrm{m}$, and $60,000 \mathrm{~N} / \mathrm{m}$, respectively. The damping values of driving wheels, guide wheels, and supporting wheels are $400 \mathrm{Ns} / \mathrm{m}, 350 \mathrm{Ns} / \mathrm{m}$, and $280 \mathrm{Ns} / \mathrm{m}$, respectively.

A ground inertia reference coordinate system is defined as $\mathbf{g}$, which contains three orthogonal unit vectors $\mathbf{g}_{1}, \mathbf{g}_{2}$, and $\mathbf{g}_{3}$. A reference coordinate system fixed to the bogie is defined as a, which contains three orthogonal unit vectors $\mathbf{a}_{1}$, $\mathbf{a}_{2}$, and $\mathbf{a}_{3}$. The positive direction of the $\mathbf{a}_{1}$-axis is the direction of the vehicle's forward speed $u$ and forms an angle with the $\mathbf{g}_{1}$-axis, the yaw angle $\psi$. The positive direction of the $\mathbf{a}_{2}$-axis is the vehicle's lateral velocity $v$. The positive directions of the $\mathbf{a}_{3}$-axis and the $\mathbf{g}_{3}$-axis are the same and are perpendicular to the ground. A reference coordinate system 
rotated to the carriage is defined as $\mathbf{b}$, which contains three orthogonal unit vectors $\mathbf{b}_{1}, \mathbf{b}_{2}$, and $\mathbf{b}_{3}$. The coordinate system transformation between $\mathbf{g}$, $\mathbf{a}$, and $\mathbf{b}$ is given in $\mathrm{Ta}-$ bles 2 and 3, respectively.

The rotation angle of the reference coordinate system $b$ relative to the reference coordinate system a is $\phi$ (roll angle). With the vehicle's kinetic energy $E_{T}$, potential energy $E_{V}$, dissipated energy $E_{D}$, and generalized force $F_{Q \phi}$, the Lagrange equation is expressed as

$$
\frac{\mathrm{d}}{\mathrm{d} t}\left(\frac{\partial E_{T}}{\partial \phi}\right)-\frac{\partial E_{T}}{\partial \phi}+\frac{\partial E_{V}}{\partial \phi}+\frac{\partial E_{D}}{\partial \phi}=F_{Q \phi} .
$$

According to the three-degree-of-freedom vehicle model, its kinetic energy, potential energy, and generalized force are derived separately. The simplified vehicle consists of a carriage and a front axle and a rear axle of the bogie.

2.2. Kinetic Energy. The total kinetic energy of the suspension-type small rail vehicle includes the kinetic energy $E_{T b}$ of the carriage, the kinetic energy $E_{T f}$ of the front axle, and the kinetic energy $E_{T r}$ of the rear axle. Each kinetic energy item includes the translational kinetic energy term and the rotational kinetic energy term.

$$
\begin{aligned}
& E_{T f}=\frac{1}{2} m_{f}\left(u_{f}^{2}+v_{f}^{2}\right)+\frac{1}{2} I_{z z f} r^{2}, \\
& E_{T r}=\frac{1}{2} m_{r}\left(u_{r}^{2}+v_{r}^{2}\right)+\frac{1}{2} I_{z z r} r^{2},
\end{aligned}
$$

where $u_{f}=u_{r}=u ; v_{f}=v+\mathrm{a} r ; v_{r}=v-\mathrm{b} r ; m_{\mathrm{f}}$ is the mass of the front axle; $m_{r}$ is the mass of the rear axle; $I_{z z f}$ is the yaw moment of inertia of the front axle; $I_{\mathrm{zzr}}$ is the yaw moment of inertia of the rear axle; and $a$ and $b$ represent the distances from the center of mass to the front and rear axle, respectively.

The reference coordinate system $\mathbf{b}$ forms a corner relative to the coordinate system a, as shown in Figure 2. If $h_{b}$ represents the distance from the carriage's center of mass to the $\mathbf{b}_{1}$-axis, the position vector $\mathbf{P}$ of the carriage's center of mass relative to the reference origin $O$ is

$$
\mathbf{P}=h_{b} \mathbf{b}_{3}=h_{b} \cos \phi \mathbf{a}_{3}-h_{b} \sin \phi \mathbf{a}_{2} .
$$

Based on the consideration of the yaw angle $\psi$ (the rotation angle of the coordinate system a relative to the coordinate system $\mathbf{g}$ ), the velocity vector of $\mathbf{P}$ in the ground reference coordinate system $\mathbf{g}$ is

$$
\frac{d \mathbf{P}^{G}}{\mathrm{~d} t}=\frac{d \mathbf{P}^{B}}{\mathrm{~d} t}+\Omega^{\mathrm{GB}} \times \mathbf{P},
$$

where $\mathbf{P}^{\mathrm{B}}$ is the velocity vector of $\mathbf{P}$ in the reference coordinate system $\mathbf{b}$ and $\Omega^{G B}$ is the angular velocity of the coordinate system $\mathbf{b}$ relative to the coordinate system $\mathbf{g}$ :

$$
\Omega^{G B}=\Omega^{G A}+\Omega^{A B}=\dot{\psi} \mathbf{a}_{3}+\dot{\phi} \mathbf{a}_{1} .
$$

Since $\mathrm{d} \mathbf{P}^{B} / \mathrm{dt}=0$, (4) can be expressed as
TABLE 2: Coordinate system transformation between $\mathbf{g}$ and $\mathbf{a}$.

\begin{tabular}{lcccc}
\hline $\mathbf{g}$ & \multicolumn{4}{c}{} \\
& $\mathbf{a}_{1}$ & $\mathbf{a}_{2}$ & $\mathbf{a}_{3}$ & \\
\hline $\mathbf{g}_{1}$ & & $\cos \psi$ & $-\sin \psi$ & 0 \\
$\mathbf{g}_{2}$ & $\sin \psi$ & $\cos \psi$ & 0 & \\
$\mathbf{g}_{3}$ & 0 & 0 & 1 & \\
\hline
\end{tabular}

TABle 3: Coordinate system transformation between $\mathbf{a}$ and $\mathbf{b}$.

\begin{tabular}{lccc}
\hline $\mathbf{a}$ & \multicolumn{3}{c}{$\mathbf{b}$} \\
& $\mathbf{b}_{1}$ & $\mathbf{b}_{2}$ & $\mathbf{b}_{3}$ \\
\hline $\mathbf{a}_{1}$ & 1 & 0 & 0 \\
$\mathbf{a}_{2}$ & 0 & $\cos \phi$ & $-\sin \phi$ \\
$\mathbf{a}_{3}$ & 0 & $\sin \phi$ & $\cos \phi$ \\
\hline
\end{tabular}

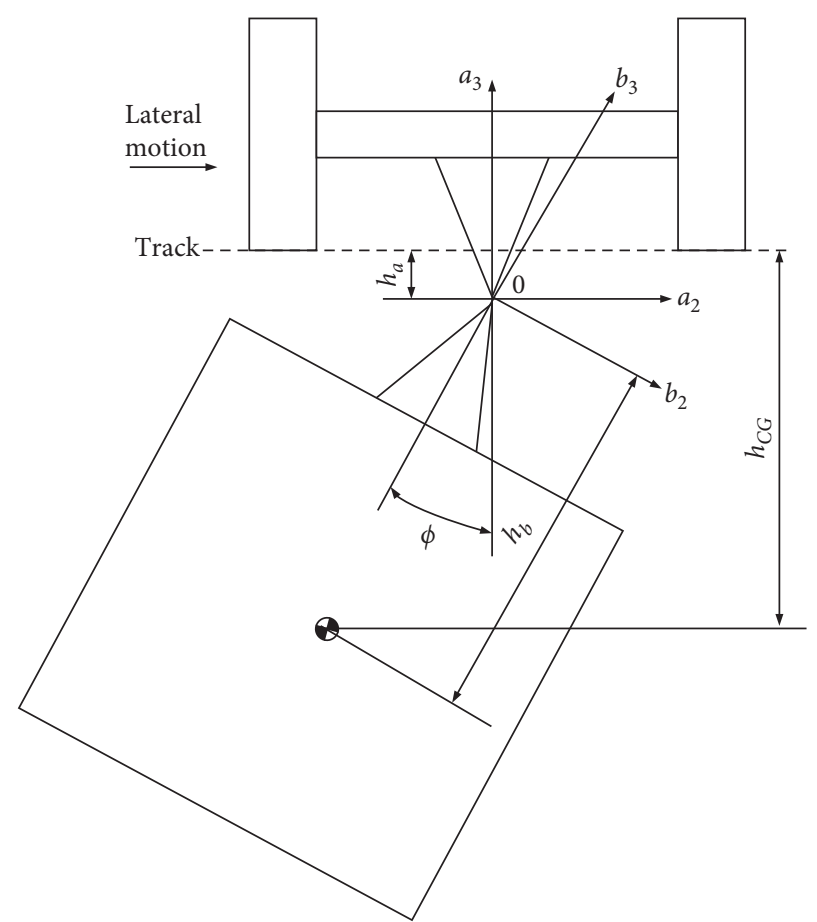

FIgURE 2: Parameters of the vehicle. $h_{a}$ : distance from the center of rotation to the track, $h_{b}$ : distance from the mass center of the carriage to the center of rotation, and $h_{C G}$ : distance from the mass center of the carriage to the track.

$$
\frac{\mathrm{d} \mathbf{P}^{G}}{\mathrm{dt}}=u_{a} \mathbf{a}_{1}+v_{b} \mathbf{a}_{2}+w_{b} \mathbf{a}_{3},
$$

where $u_{b}, v_{b}$, and $w_{b}$ are the forward speed, lateral velocity, and vertical speed of the carriage, respectively.

$$
\left\{\begin{array}{l}
u_{b}=u+h_{b} \dot{\phi} \sin \phi, \\
v_{b}=v-h_{b} \dot{\phi} \cos \phi, \\
w_{b}=h_{b} \dot{\phi} \sin \phi .
\end{array}\right.
$$

The translational kinetic energy of the carriage is defined as $E_{T b-t}$ : 


$$
E_{T b-t}=\frac{1}{2} m_{b}\left(u_{b}^{2}+v_{b}^{2}+w_{b}^{2}\right),
$$

where $m_{b}$ is the mass of the carriage.

The rotational kinetic energy of the carriage is defined as $E_{T b-r}:$

$$
E_{T b-r}=\frac{1}{2}\left(\Omega^{\mathrm{GB}}\right)^{T} I_{b} \Omega^{\mathrm{GB}},
$$

where $I_{b}$ is the moment of inertia matrix of the car quality.

In the reference coordinate system $\mathbf{b}, I_{b}$ is a constant matrix:

$$
I_{b}=\left(\begin{array}{ccc}
I_{11} & -I_{12} & -I_{13} \\
-I_{12} & I_{22} & -I_{23} \\
-I_{13} & -I_{23} & I_{33}
\end{array}\right),
$$

where $I_{i i}$ is the inertia of the vector $\mathbf{b}_{i}$ through the center of mass of the carriage and $I_{i j}$ is the product of inertia.

Since matrix $I_{b}$ is constant in the reference coordinate system b, according to equation (5) and the coordinate system transformation relationship, $\Omega^{G B}$ can be expressed as

$$
\Omega^{\mathrm{GB}}=\dot{\phi} \mathbf{b}_{1}+\dot{\psi} \sin \phi \mathbf{b}_{2}+\dot{\psi} \cos \phi \mathbf{b}_{3} .
$$

The rotational kinetic energy of the carriage, $E_{T b-r}$, can be expressed as

$$
\begin{aligned}
E_{T b-r} & =\frac{1}{2} \times\left(\begin{array}{c}
\dot{\phi} \\
\dot{\psi} \sin \phi \\
\dot{\psi} \cos \phi
\end{array}\right)^{T} \times\left(\begin{array}{ccc}
I_{11} & 0 & -I_{13} \\
0 & I_{22} & 0 \\
-I_{13} & 0 & I_{33}
\end{array}\right) \times\left(\begin{array}{c}
\dot{\phi} \\
\dot{\psi} \sin \phi \\
\dot{\psi} \cos \phi
\end{array}\right) \\
& =\frac{1}{2}\left(I_{11} \dot{\phi}^{2}-2 I_{13} \dot{\phi} \dot{\psi} \cos \phi+I_{33} \dot{\psi}^{2} \cos ^{2} \phi+I_{22} \dot{\psi}^{2} \sin ^{2} \phi\right) .
\end{aligned}
$$

Since the inertia product terms of roll and yaw are relatively small compared to the roll and yaw inertia, the second term is usually negligible. The fourth term is a fourthorder term and can also be ignored.

2.3. Potential Energy and Dissipated Energy. The potential energy of the carriage can be expressed as

$$
E_{V \phi}=\frac{1}{2} K_{\phi} \phi^{2},
$$

where $K_{\phi}$ is the roll stiffness coefficient.

The dissipated energy of the carriage can be expressed as

$$
E_{D \phi}=\frac{1}{2} C_{\phi} \dot{\phi}^{2},
$$

where $C_{\phi}$ is the roll damping coefficient.

In addition, it is necessary to consider the change in potential energy caused by the height of the carriage's center of mass when the vehicle rolls:

$$
E_{V g}=m_{b} g h_{b}(1-\cos \phi) .
$$

2.4. Generalized Force. The generalized force $F_{Q \phi}$ depends on the torque of the height of the reference roll axis. For a two-axle vehicle, the generalized force corresponding to the roll torque of the carriage can be expressed as

$$
F_{Q \phi}=\left(h_{a f}-h_{a O}\right) F_{y f}+\left(h_{a r}-h_{a O}\right) F_{y r},
$$

where $h_{a f}$ is the distance between the front axle and the rail; $h_{a r}$ is the distance between the rear axle and the rail; $F_{y f}$ is the lateral force of the rail applied on the front wheel; and $F_{y r}$ is the lateral force of the rail applied on the rear wheel.

2.5. Dynamic Equation. According to the Lagrange equation, when the vehicle's forward velocity is constant, the differential equations of the lateral speed $v$, lateral yaw rate $r$, and carriage roll angle $\varphi$ are, respectively, expressed as follows:

$$
\begin{aligned}
& \qquad \begin{array}{l}
\left(m_{b}+m_{f}+m_{r}\right)\left(\dot{v}+u_{c} r\right)+\left(a m_{f}-b m_{r}\right) \dot{r}-m_{b} h_{b} \ddot{\phi}=F_{y f}+F_{y r}, \\
\qquad\left(a m_{f}-b m_{r}\right)\left(\dot{v}+u_{c} r\right)+I_{z z} \dot{r}+I_{x z} \ddot{\phi}=a F_{y f}-b F_{y r},
\end{array} \\
& \begin{array}{l}
I_{x x} \ddot{\phi}+C_{\phi} \dot{\phi}+\left(K_{\phi}+m_{b} g h_{b}\right) \phi-m_{b} h_{b}\left(\dot{v}+u_{c} r\right)+I_{x z} \dot{r}=d_{f} F_{y f}+d_{r} F_{y r}, \\
I_{x x}=I_{x x b}+m_{b} h_{b}^{2}, \\
I_{z z}=I_{z z b}+I_{z z f}+I_{z z r}+m_{f} a^{2}+m_{r} b^{2}, \\
\text { the carriage for the } \mathbf{a}_{1} \text {-axis; } I_{z z} \text { is } \\
d_{f} \approx h_{a f}-h_{a O}, \\
\text { tion; } d_{f} \text { is the lateral deviation of } \\
d_{r} \approx h_{a r}-h_{a O} .
\end{array}
\end{aligned}
$$

where $I_{x x}$ is the roll inertia of the carriage for the $\mathbf{a}_{1}$-axis; $I_{z z}$ is the yaw inertia of the carriage for the $\mathbf{a}_{3}$-axis; $I_{x z}$ is the inertia product of roll and yaw motion; $d_{f}$ is the lateral deviation of the front axle caused by the unit roll angle of the carriage; and $d_{r}$ is the lateral deviation of the rear axle caused by the unit roll angle of the carriage. s 
Assuming that the tire lateral force $F_{y}$ has a linear relationship with the tire's side slip angle and vertical load, the lateral forces of the front and rear wheels can be expressed as

$$
\begin{aligned}
& F_{y f}=-C_{\alpha f} \alpha_{f}=-C_{\alpha f}\left(\frac{v+a r}{u_{c}}-\delta_{f}\right), \\
& F_{y r}=-C_{\alpha r} \alpha_{r}=-C_{\alpha r} \frac{v-b r}{u_{c}}
\end{aligned}
$$

$$
\begin{aligned}
\left(\begin{array}{c}
-m_{b} h_{b} \ddot{\phi} \\
0 \\
I_{x x} \ddot{\phi}
\end{array}\right)+\left(\begin{array}{c}
m \dot{v}+\left(a m_{f}-b m_{r}\right) \dot{r} \\
\left(a m_{f}-b m_{r}\right) \dot{v}+I_{z z} \dot{r} \\
-m_{b} h_{b} \dot{v}+C_{\phi} \dot{\phi}
\end{array}\right)+\left(\begin{array}{c}
\left(\frac{C_{\alpha f}+C_{\alpha r}}{u_{c}}\right) v+\left(m u_{c}+\frac{a C_{\alpha f}-b C_{\alpha r}}{u_{c}}\right) r \\
\left(\frac{a C_{\alpha f}-b C_{\alpha r}}{u_{c}}\right) v+\left[\frac{a^{2} C_{\alpha f}+b^{2} C_{\alpha r}}{u_{c}}+\left(a m_{f}-b m_{r}\right) u_{c}\right] r \\
\left(\frac{d_{f} C_{\alpha f}+d_{r} C_{\alpha r}}{u_{c}}\right) v+\left(\frac{a d_{f} C_{\alpha f}-b d_{r} C_{\alpha r}}{u_{c}}-m_{b} h_{b} u_{c}\right) r+\left(K_{\phi}+m_{b} g h_{b}\right) \phi
\end{array}\right) \\
=\left(\begin{array}{c}
C_{\alpha f} \\
a C_{\alpha f} \\
d_{f} C_{\alpha f}
\end{array}\right) \arcsin \left(\frac{a+b}{R}\right) .
\end{aligned}
$$

where $a_{f}$ and $a_{r}$ are, respectively, the side slip angles of the front and rear wheels; $r$ is the yaw rate; and $\delta_{f}$ is the steering angle.

The turning radius $R$ can be expressed as

$$
R=\frac{a+b}{\sin \delta_{f}} .
$$

Then, equations (17)-(19) can be rewritten as
In this section, the dynamic analysis of the suspended rail vehicle increases the theoretical understanding of this system, provides a theoretical basis for the establishment of the simulation model, and gives the key parameters influencing the vehicle's driving stationarity for the selection of optimization parameters. It can be seen from the equation derivation process that the design parameters of the bogie have greater influences on the dynamic performance of the suspended rail vehicle. Based on the influence trend analysis, relevant parameters are optimized in the following.

\section{Simulation and Analysis of Driving Conditions of the Suspension-Type Small Rail Vehicle}

3.1. Model Creation of the Single Bogie. Multibody dynamics simulation platform SimulationX was used to model the system. The vehicle is simplified as a system consisting of mass block, guide wheels, driving wheels, and supporting wheels, as shown in Figure 3 [24, 25]. As for the guide wheel, the shape of the rail (straight or curved) is expressed by setting a contact contour line. The driving wheel is simulated as a common tire model. Since the differential control mode should be set for the hub motor needs according to different turning radii, the simulation model is simplified to a differential mechanism in order to adapt to different turning radii. The interaction force between the supporting wheel and the vehicle is expressed by a formula, and the force is related to the displacement and velocity of the vehicle in the vertical direction.

The basic parameters of the bogie are provided as follows: driving wheel tread $(374 \mathrm{~mm})$, the center of mass ( $1.5 \mathrm{~m}$ below the driving wheel axis), guide wheel tread $(340 \mathrm{~mm})$, and zero supporting wheel.

3.2. Analysis of the Single-Bogie Simulation Results. The attitude and oscillation characteristics of the vehicle under the two driving conditions along a straight line and a bend are, respectively, analyzed $[26,27]$. The velocity of the vehicle is $80 \mathrm{Km} / \mathrm{h}$ in a straight line and $25 \mathrm{Km} / \mathrm{h}$ in a bend with the steering angle of $90^{\circ}$ and the turning radius of $20 \mathrm{~m}$.

The change of the vehicle attitude angle along a straight line is shown in Figure 4. The initial amplitude of vehicle roll angle is small, and once the guide wheel contacts the side wall of the rail, the vehicle starts to oscillate. When one side of the vehicle contacts with the rail, the roll angle of the vehicle tends to diverge. The pitch angle decays and oscillates at the beginning of driving. The initial attitude of the vehicle is small and can be disregarded. The yaw angle of the vehicle at the initial moment is 0 . When the vehicle starts to roll, the yaw angle also starts to oscillate with the same frequency to the roll angle, and they are coupled to each other.

Figure 5 shows the lateral velocity of the vehicle running along a straight line. The lateral velocity of the vehicle is 0 at 


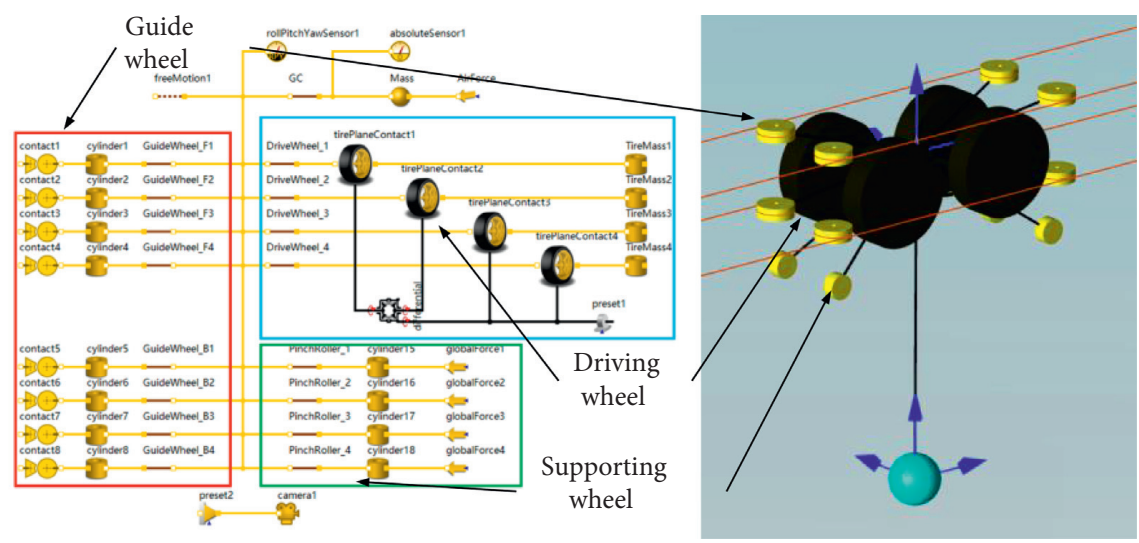

Figure 3: Dynamic model of the vehicle.

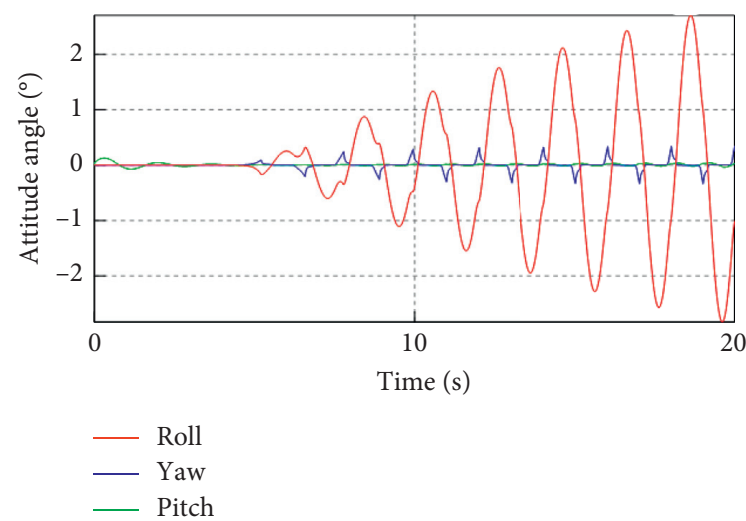

FIGURE 4: Change of the attitude angle of the vehicle using a singlebogie structure on straight driving.

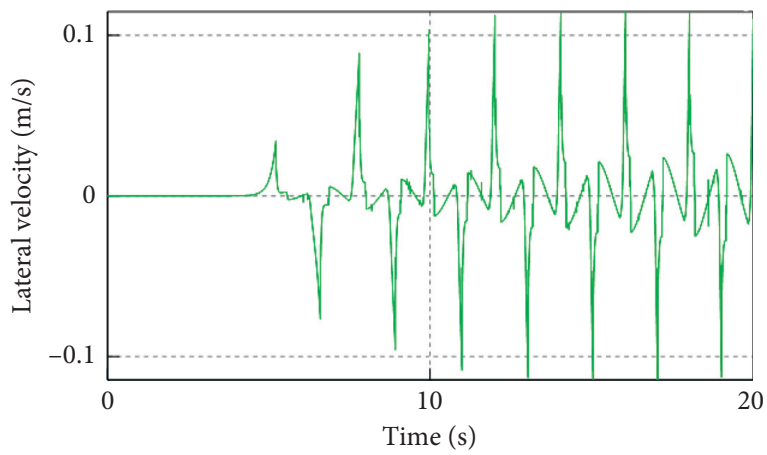

FIGURE 5: Change of the lateral velocity of the vehicle using a singlebogie structure on straight driving.

the initial stage, but the lateral force of friction on the wheels cannot balance the lateral inertial force of the vehicle when it yaws. Therefore, the oscillation period of the lateral velocity is the same as that of the yaw angle. The fluctuation of the curve in the figure is also related to the friction and damping of vehicle tires.

The changes of roll angle and pitch angle on vehicle's bend driving are shown in Figure 6. The pitch angle has a certain amplitude at the initial position and then gradually decays. The initial oscillation amplitude of the pitch angle is

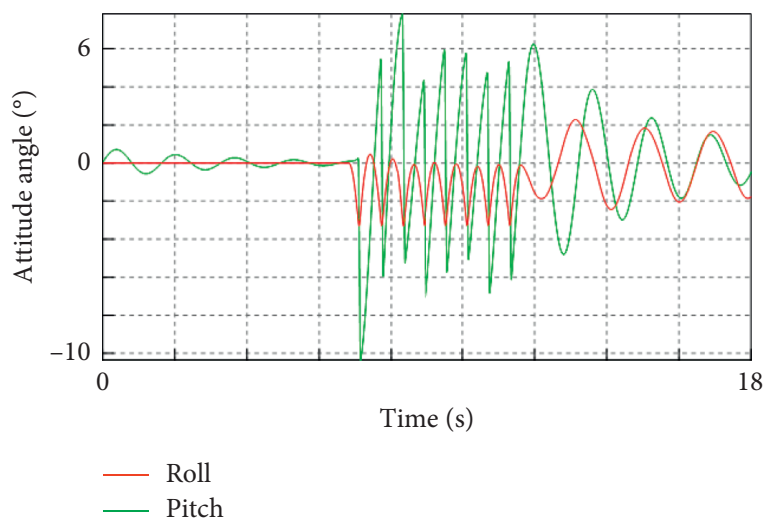

Figure 6: Change of the attitude angle of the vehicle using a singlebogie structure on bend driving.

related to the vehicle's initial attitude. The vehicle enters the bend at the $7^{\text {th }}$ second, and the roll angle and pitch angle oscillate with different frequencies. After the bend driving is completed at the $11^{\text {th }}$ second, the oscillation of the two attitude angles continues with slow damping.

The large amplitude of the oscillation of the attitude angle of the vehicle driving on a curved track seriously affects the stationarity and safety of the vehicle. Therefore, the structural parameters of the vehicle need to be optimized in order to improve the driving stationarity. The five factors that affect the vehicle driving stationarity are analyzed comprehensively, including the tread of the driving wheel, the center of mass of the vehicle, the introduction of the supporting wheel, the tread of the supporting wheel, and the tread of the guide wheel.

3.3. Influence of Key Parameters of the Single-Bogie Vehicle. The design parameters of the vehicle are adjusted according to the following maximum allowable ranges:

(1) Introduction of the supporting wheels: the tread of the driving wheel is $374 \mathrm{~mm}$; the center of mass is $1.5 \mathrm{~m}$ below the axis of the driving wheel; the tread of the guide wheel is $340 \mathrm{~mm}$; the tread of the supporting wheel is $322 \mathrm{~mm}$ 
(2) Optimization of the tread of the driving wheel: the adjusting range of the tread of the driving wheel is $374 \mathrm{~mm}$ to $574 \mathrm{~mm}$; the center of mass is $1.5 \mathrm{~m}$ below the axis of the driving wheel; the tread of the guide wheel is $340 \mathrm{~mm}$; the tread of the supporting wheel is $322 \mathrm{~mm}$

(3) Optimization of the center of mass position: the tread of the driving wheel is $374 \mathrm{~mm}$; the distance between the center of mass and the axis of the driving wheel is adjusted from $1.1 \mathrm{~m}$ to $1.5 \mathrm{~m}$; the tread of the guide wheel is $340 \mathrm{~mm}$; the tread of the supporting wheel is $322 \mathrm{~mm}$

(4) Optimization of the tread of the guide wheel: the tread of the driving wheel is $374 \mathrm{~mm}$; the center of mass is $1.5 \mathrm{~m}$ below the axis of the driving wheel; the adjustment range of the tread of the guide wheel is $340 \mathrm{~mm}$ to $540 \mathrm{~mm}$; the tread of the supporting wheel is $322 \mathrm{~mm}$

(5) Optimization of the tread of the supporting wheel: the tread of the driving wheel is $374 \mathrm{~mm}$; the center of mass is $1.5 \mathrm{~m}$ below the axis of the driving wheel; the tread of the guide wheel is $340 \mathrm{~mm}$; the adjustment range of the tread of the supporting wheel is $322 \mathrm{~mm}$ to $522 \mathrm{~mm}$

\subsubsection{Influence of the Introduction of the Supporting Wheel.} In order to reduce the amplitude of each attitude angle and restrain the divergence of the vehicle's roll angle, supporting wheels are installed on the vehicle. The attitude angle and lateral velocity of the vehicle running along a straight line are shown in Figure 7. After installing the supporting wheels, the pitch oscillations attenuate rapidly, and no obvious oscillation occurs in the whole process. Moreover, the roll angle of the vehicle no longer diverges, and the amplitude decreases significantly to $\pm 1.15^{\circ}$. The change and amplitude of the lateral velocity of the vehicle are similar to those before the introduction of the supporting wheel. The amplitude of oscillation is $0.11 \mathrm{~m} / \mathrm{s}$.

The pitch angle and roll angle of the vehicle on bend driving are shown in Figure 8. The roll angle remains stable, and the pitch angle converges rapidly after a small amplitude fluctuation from 0 to 7 seconds. After 7 seconds, the vehicle enters the bend. The roll angle and pitch angle oscillate greatly, and corresponding amplitudes are $3.27^{\circ}$ and $4.16^{\circ}$, respectively. However, the two attitude angles attenuate rapidly and tend to level off before the vehicle leaves the bend. The vehicle leaves the bend at the $11^{\text {th }}$ second. After that, the roll angle fluctuates greatly and displays a convergence trend, whereas the pitch angle tends to be stable.

3.3.2. Influence of the Driving Wheel Tread. When the distance between the center of mass and the axis of the driving wheels, the guide wheel tread, and the supporting wheel tread remain unchanged, the driving wheel tread gradually increases from $374 \mathrm{~mm}$ to $574 \mathrm{~mm}$ so as to explore the influence of the driving wheel tread. When the vehicle travels straight, the changes of attitude angle and lateral velocity are, respectively, shown in Figures 9 and 10. The variations of the amplitude of the roll angle with the design parameters of the bogie are shown in Figure 11. The amplitude of the roll angle decreases from $1.15^{\circ}$ to $0.8^{\circ}$ with the increase in the driving wheel tread. According to the statistical data, with the increase in the driving wheel tread, the amplitude of the yaw angle does not change significantly and only fluctuates around $0.3^{\circ}$. With the increase in the driving wheel tread, the amplitude of lateral velocity decreases slightly, and the decrease is negligible.

The changes of the attitude angle of the vehicle on the bend driving are shown in Figure 12, and the variations of the amplitude and settling time of the attitude angle with different design parameters of the bogie are shown in Figure 13. The amplitude of the oscillation of the vehicle roll angle and the settling time of the first oscillation of the roll angle decrease with the increase in the driving wheel tread, but the settling time of the second oscillation of the roll angle does not change significantly with the change in the driving wheel tread. The amplitude and the settling time of pitch oscillation also decrease with the increase in the driving wheel tread.

\subsubsection{Influence of the Center of Mass of the Carriage.} When the driving wheel tread, guide wheel tread, and supporting wheel tread remain unchanged, the distance between the center of mass and the axis of the driving wheel gradually decreases from $1.5 \mathrm{~m}$ to $1.1 \mathrm{~m}$ so as to explore the influence of the position of the center of mass. When the center of mass is, respectively, $1.5 \mathrm{~m}$ and $1.1 \mathrm{~m}$ below the axis of the driving wheel on straight driving, the changes of attitude angle and lateral velocity are, respectively, shown in Figures 14 and 15 . The variations of the amplitude of the roll angle with the design parameters of the bogie are shown in Figure 11. It can be seen that the amplitude of the vehicle's roll angle decreases from $1.15^{\circ}$ to $0.95^{\circ}$. According to the statistical data, the amplitude of the yaw angle decreases slightly and can be ignored. The amplitude of the lateral velocity decreases slightly from $0.11 \mathrm{~m} / \mathrm{s}$ to $0.101 \mathrm{~m} / \mathrm{s}$.

When the center of mass is, respectively, $1.5 \mathrm{~m}$ and $1.1 \mathrm{~m}$ below the axis of the driving wheel, the roll angle and pitch angle of the vehicle on bend driving are shown in Figure 16, and the variations of the amplitude and settling time of the attitude angle with different design parameters of the bogie are shown in Figure 13. The amplitude and the settling time of oscillation of the roll angle decrease rapidly. Especially, the settling time of roll angle's first oscillation significantly decreases, indicating that, with the decrease in the distance away from the driving wheel axis, the stability restoration from roll angle's first oscillation becomes fast. The amplitude and the settling time of pitch angle's oscillation also decrease rapidly, indicating that the stability restoration time of the pitch angle is significantly shortened with the decrease in the distance between the center of mass and the axis of the driving wheel.

3.3.4. Influence of the Guide Wheel Tread. When the center of mass, the driving wheel tread, and the supporting wheel tread remain unchanged, the guide wheel tread gradually 


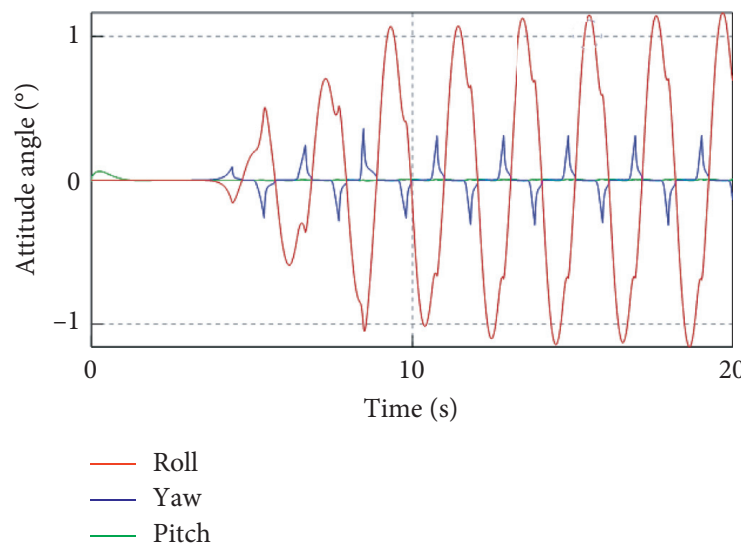

(a)

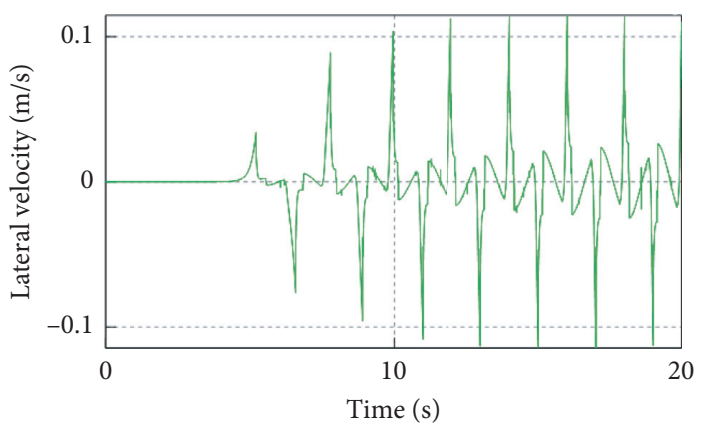

(b)

FIgURE 7: Changes of the single-bogie vehicle after the introduction of supporting wheels. (a) Attitude angle. (b) Lateral velocity.

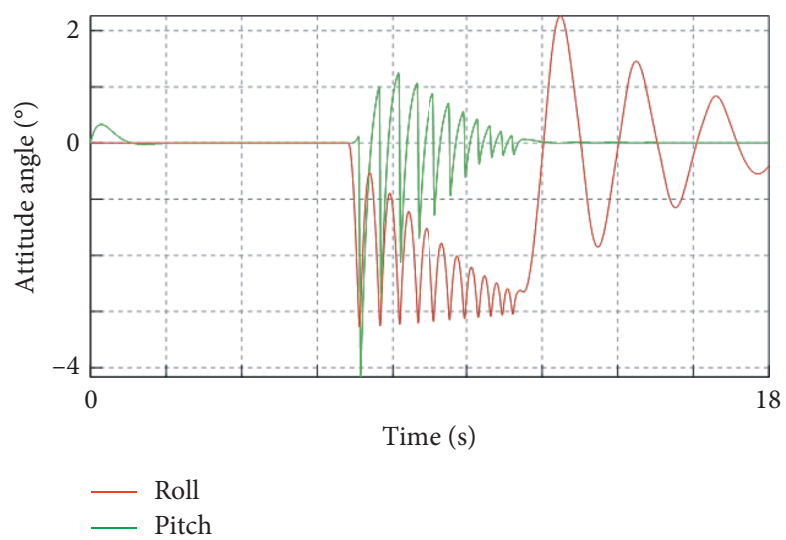

FIGURE 8: Change of the attitude angle of the single-bogie vehicle after the introduction of the supporting wheels.

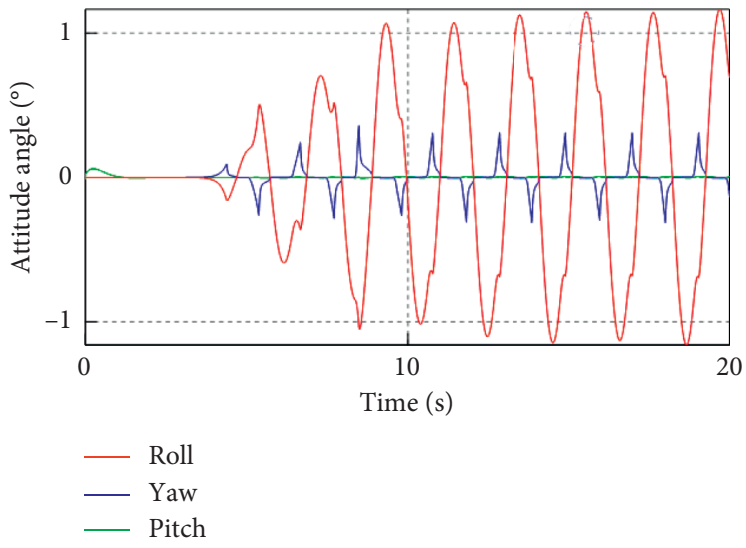

(a)

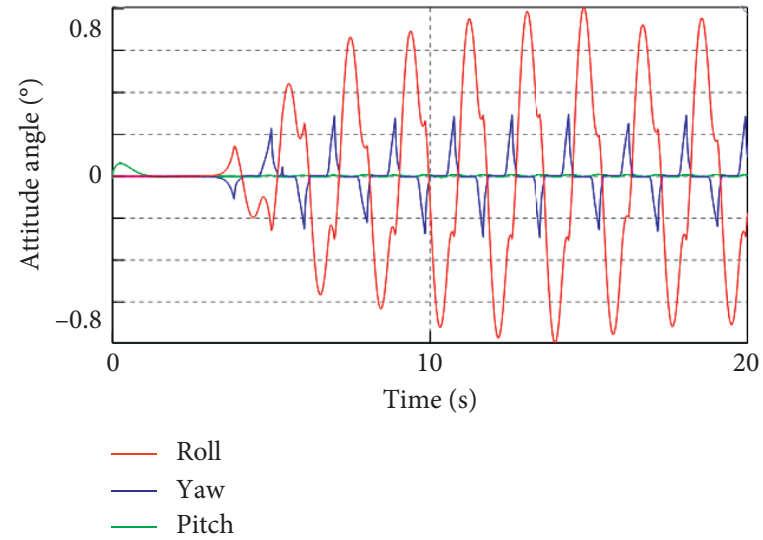

(b)

Figure 9: Change in the attitude angle of the single-bogie vehicle under different driving wheel treads. (a) $374 \mathrm{~mm}$. (b) $574 \mathrm{~mm}$.

increases from $340 \mathrm{~mm}$ to $540 \mathrm{~mm}$ so as to explore the influence of the guide wheel tread. When the vehicle travels straight, the changes of the attitude angle and lateral velocity are, respectively, shown in Figures 17 and 18. The variations of the amplitude of the roll angle with the design parameters of the bogie are shown in Figure 11. With the increase in the guide wheel tread, the amplitude of the roll angle decreases slightly from $1.15^{\circ}$ to $1.12^{\circ}$, and the decrease is negligible. With the increase in the guide wheel tread, the amplitude of the yaw angle increases slightly from $0.300^{\circ}$ to $0.306^{\circ}$, and the increase is negligible. With the increase in the guide wheel tread, the amplitude of the lateral velocity decreases slightly, 


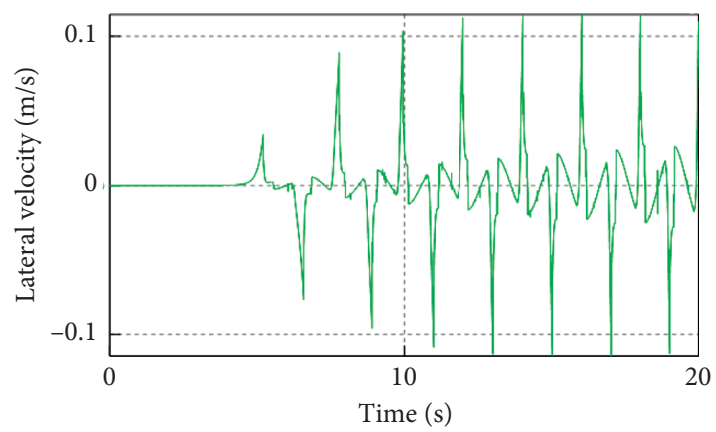

(a)

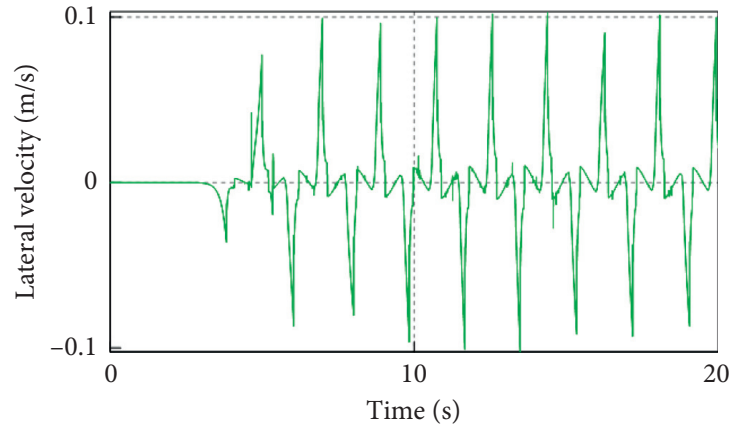

(b)

Figure 10: Change in the lateral velocity under different driving wheel treads. (a) $374 \mathrm{~mm}$. (b) $574 \mathrm{~mm}$.

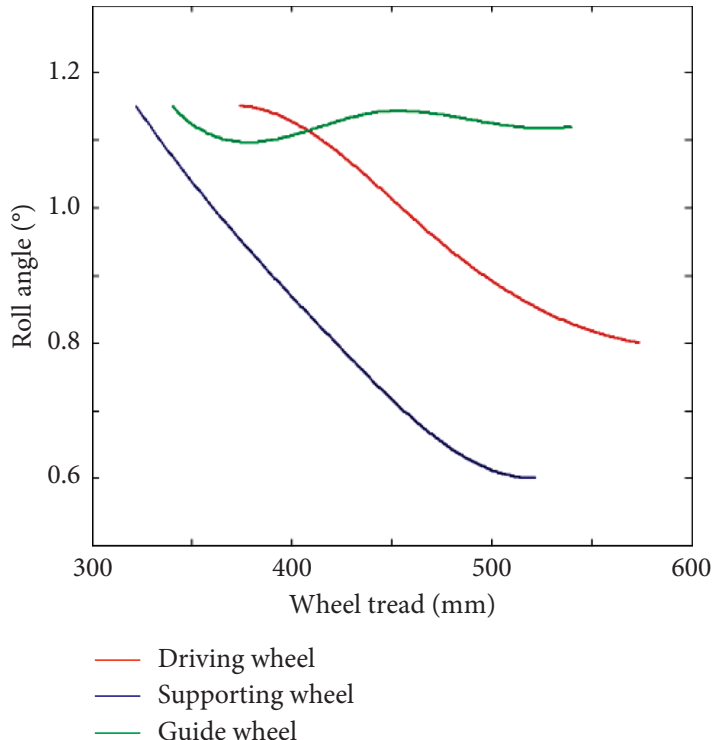

(a)

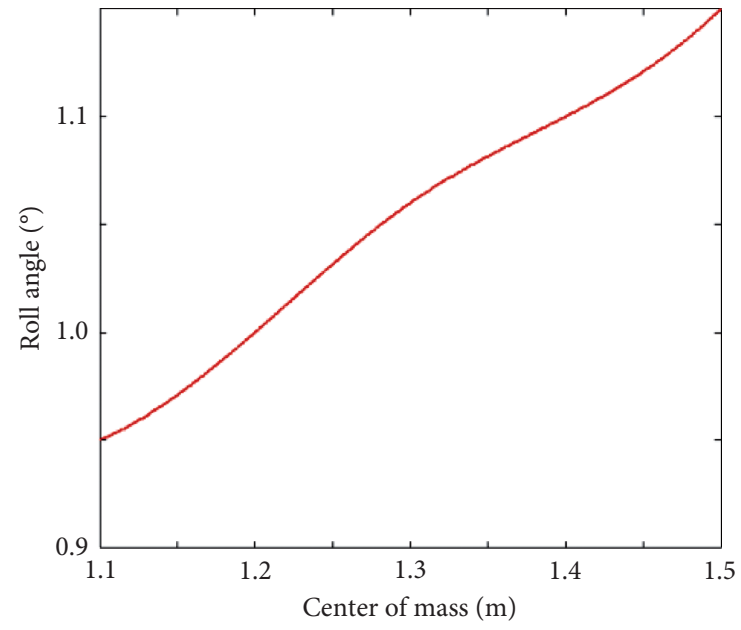

(b)

FIGURE 11: Variations of the amplitude of the roll angle with the design parameters of the bogie on straight driving: (a) wheel tread and (b) center of mass.

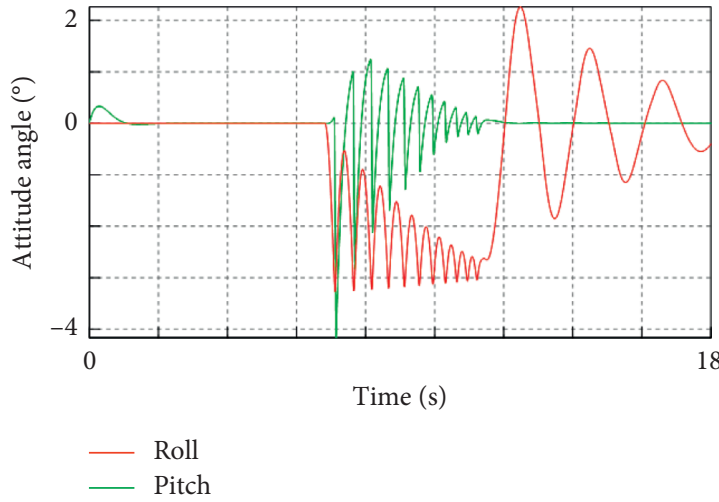

(a)

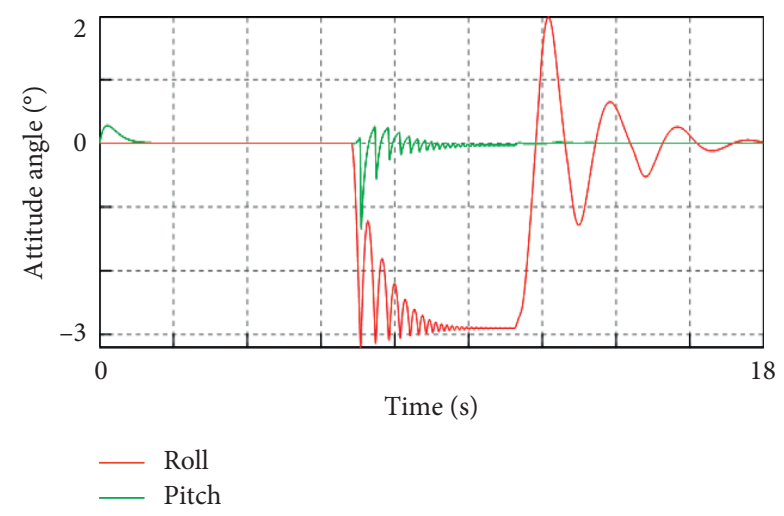

(b)

Figure 12: Change of the attitude angle on bend driving under different driving wheel treads. (a) $374 \mathrm{~mm}$. (b) $574 \mathrm{~mm}$. 

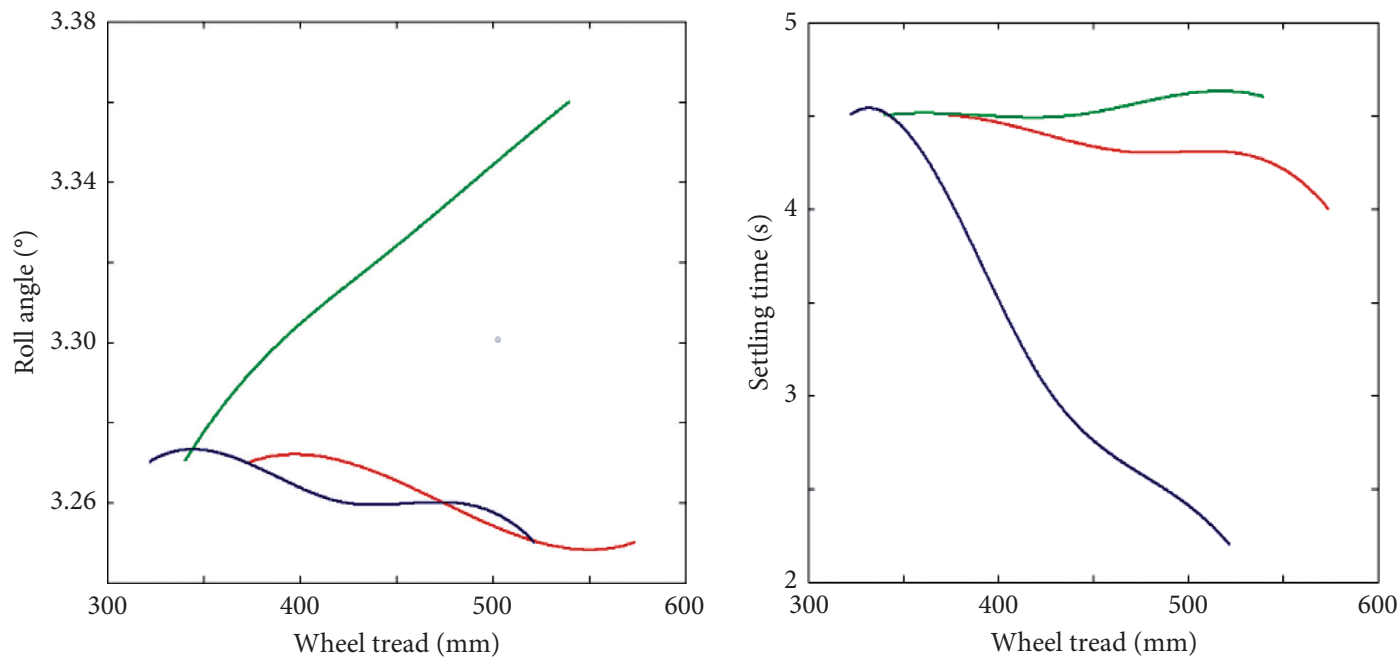

- Driving wheel

— Supporting wheel

_ Guide wheel

— Driving wheel

- Supporting wheel

— Guide wheel

(a)
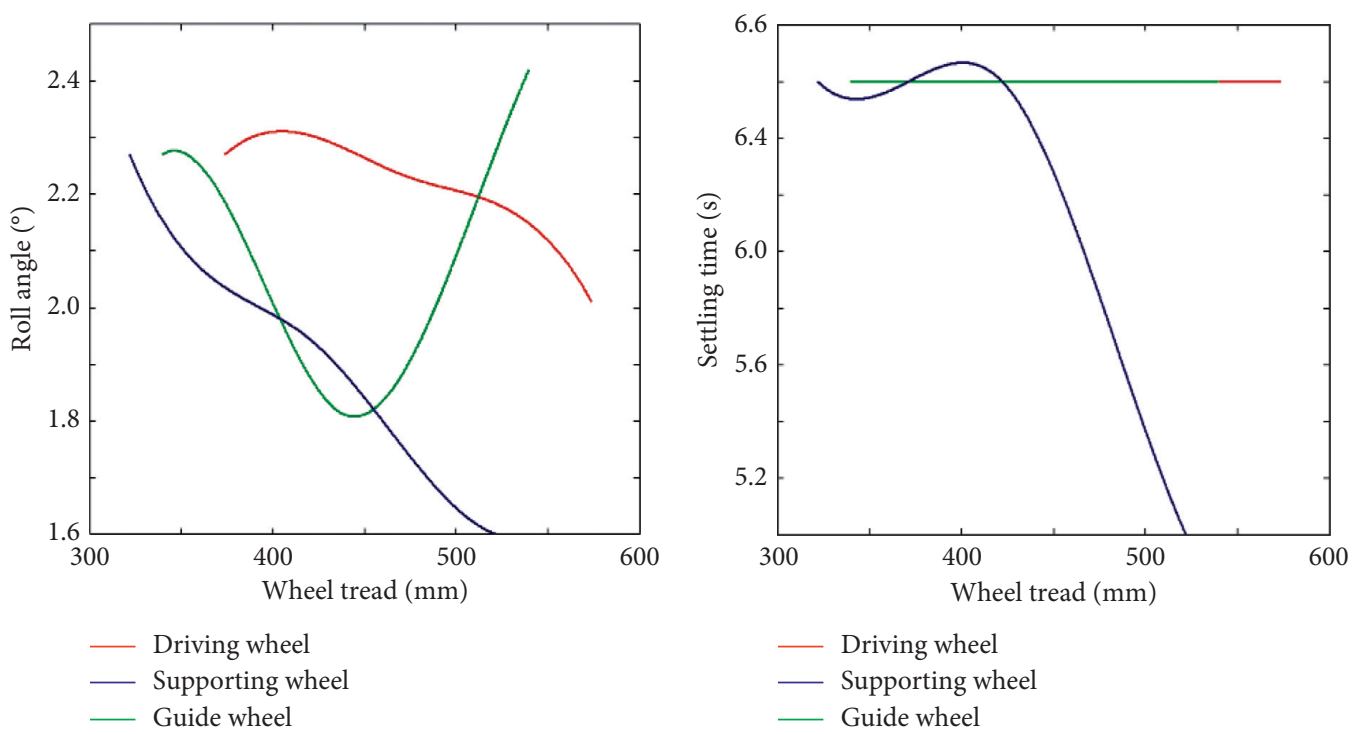

(b)

Figure 13: Continued. 

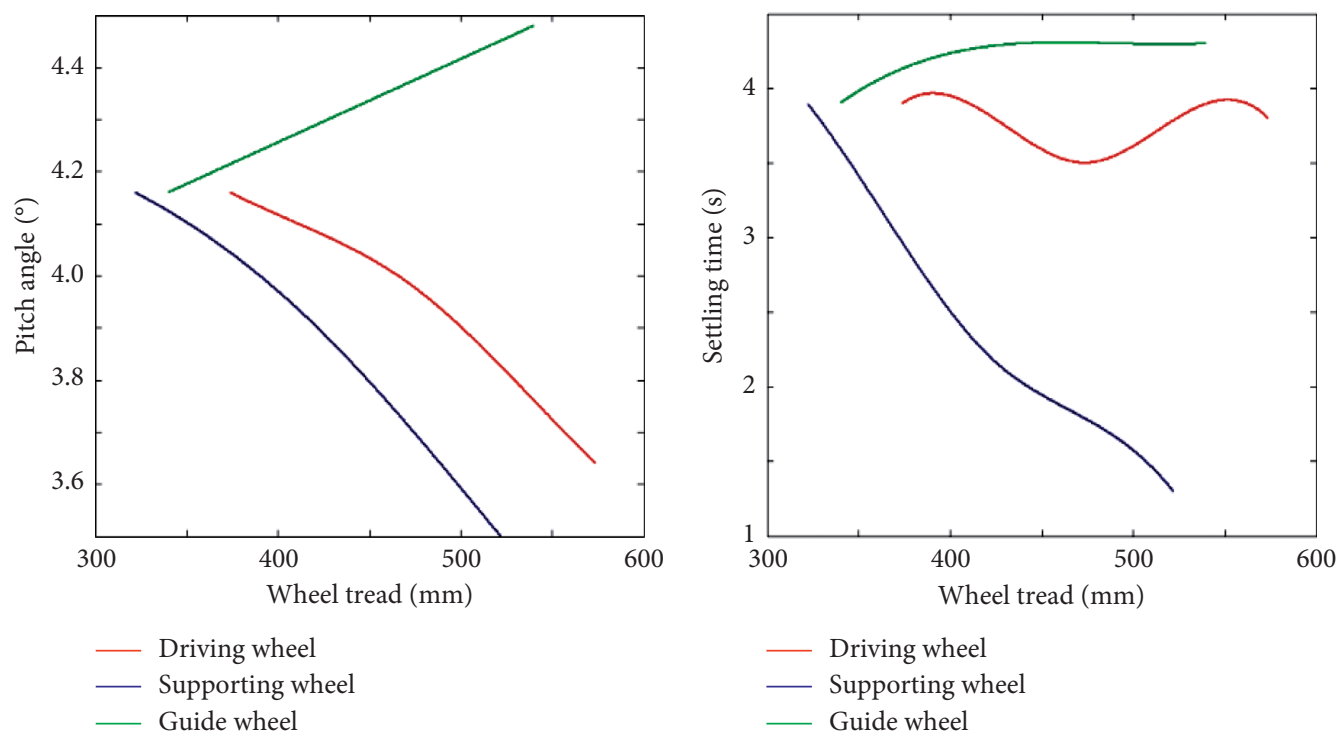

(c)
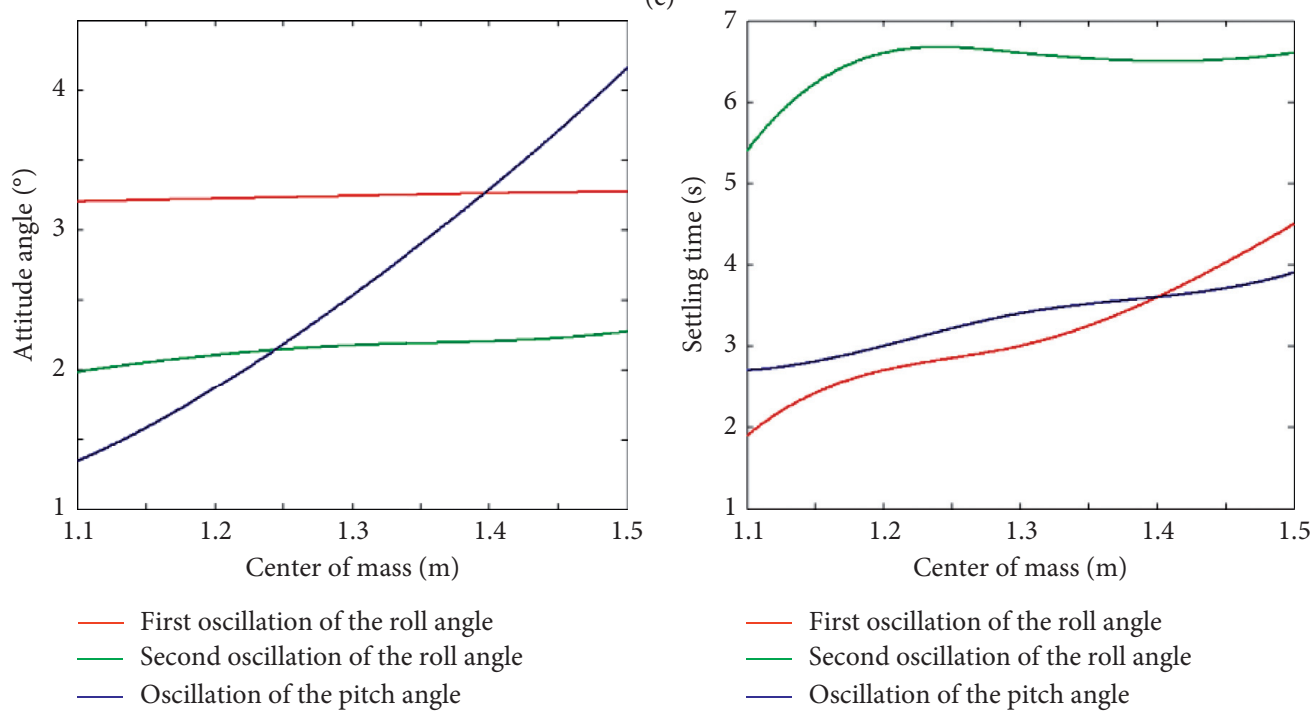

(d)

FIGURE 13: Variations of the amplitude and settling time of the attitude angle with different design parameters of the bogie on bend driving: (a) the first oscillation of the roll angle; (b) the second oscillation of the roll angle; (c) the oscillation of the pitch angle; (d) the influence of changes of the center of mass position on the attitude angle and settling time.

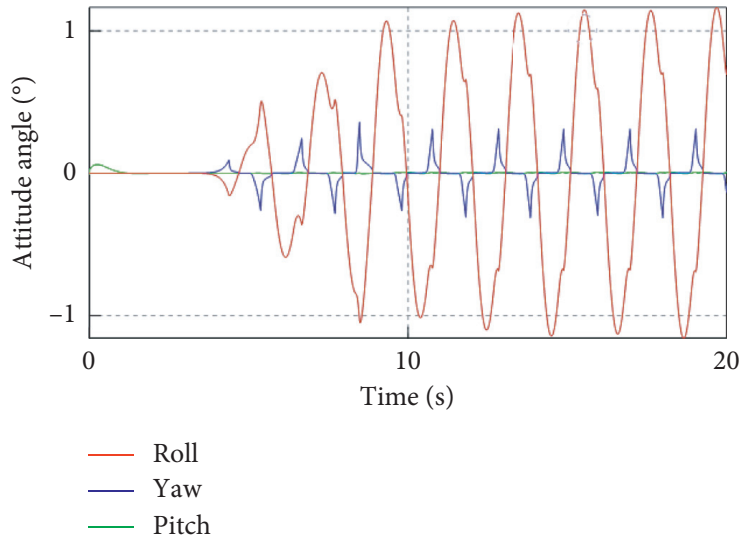

(a)

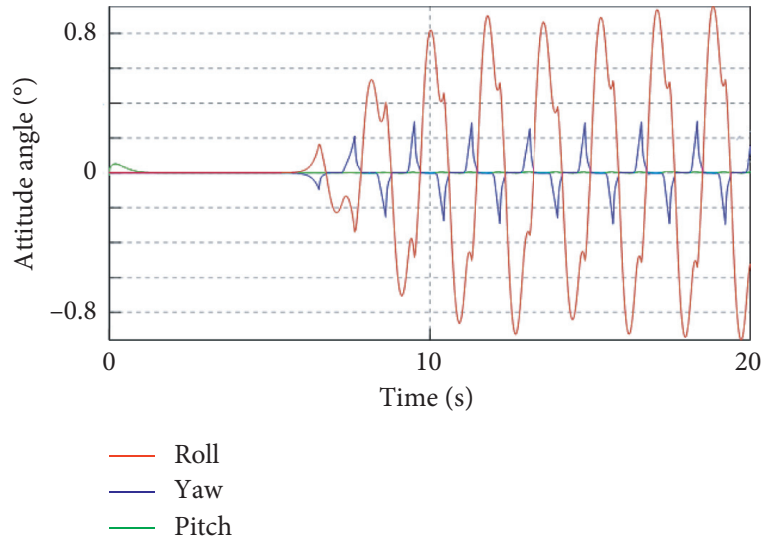

(b)

Figure 14: Changes of the attitude angle when the center of mass is (a) $1.5 \mathrm{~m}$ and (b) $1.1 \mathrm{~m}$ below the axis of the driving wheel. 


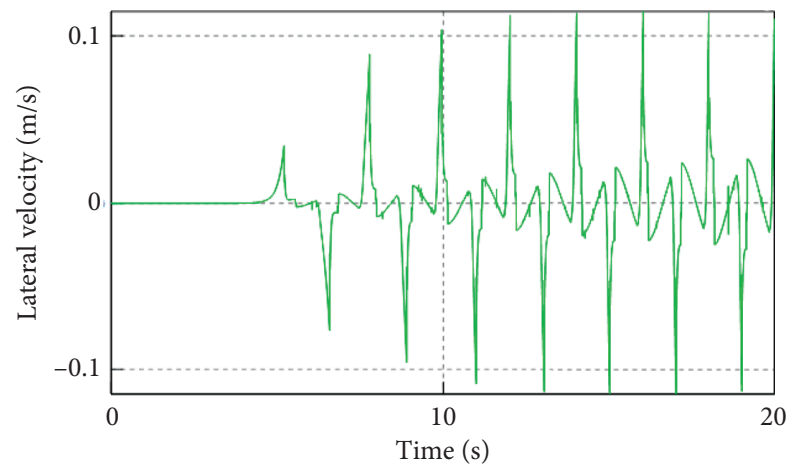

(a)

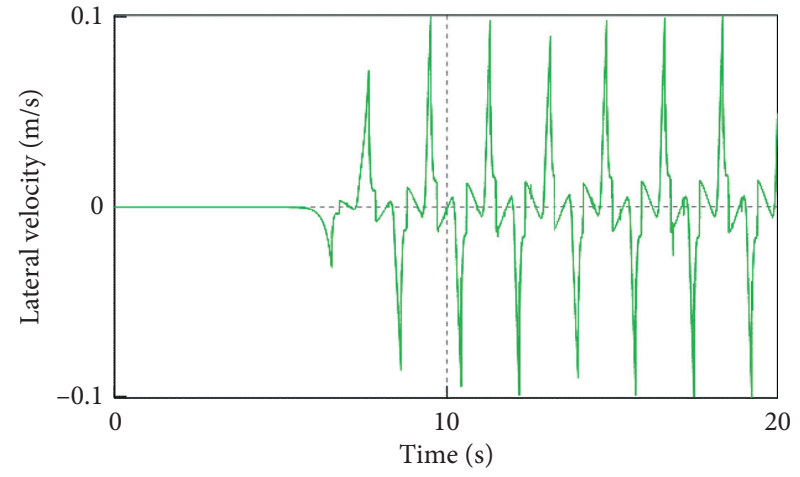

(b)

FIGURE 15: Changes of the lateral velocity when the center of mass is (a) $1.5 \mathrm{~m}$ and (b) $1.1 \mathrm{~m}$ below the axis of the driving wheel.

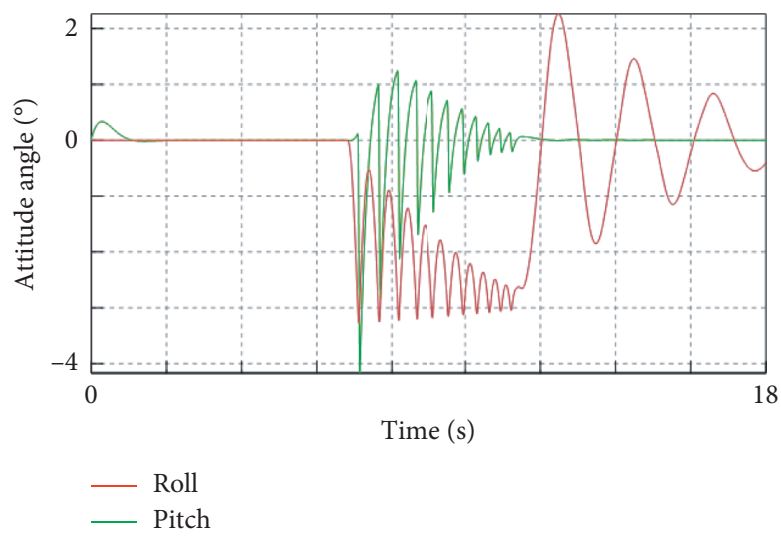

(a)

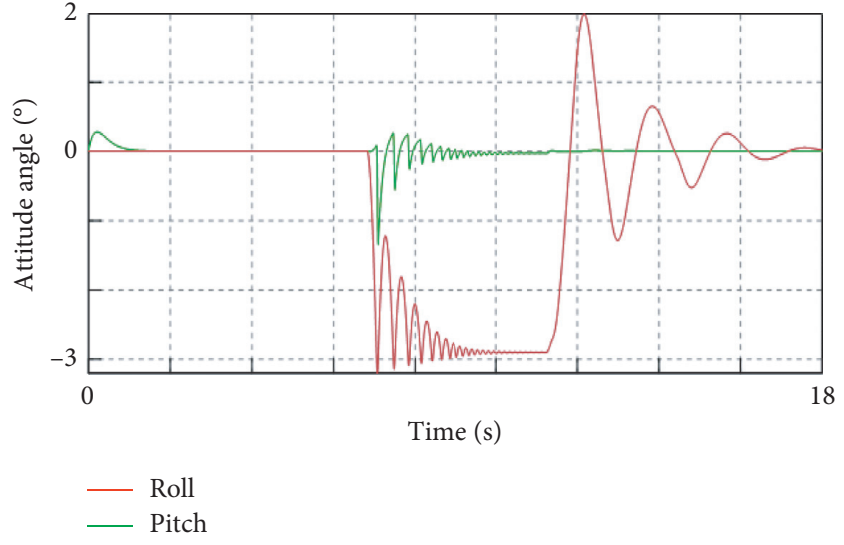

(b)

Figure 16: Changes of the attitude angle when the center of mass is (a) $1.5 \mathrm{~m}$ and (b) $1.1 \mathrm{~m}$ below the axis of the driving wheel.

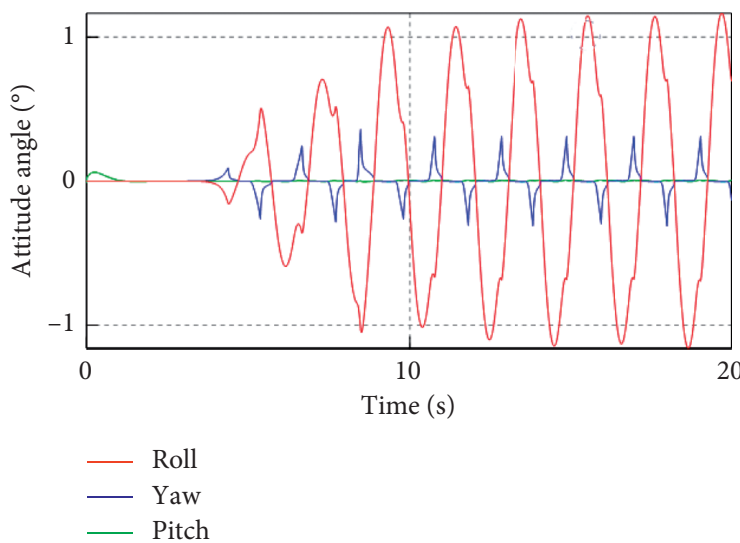

(a)

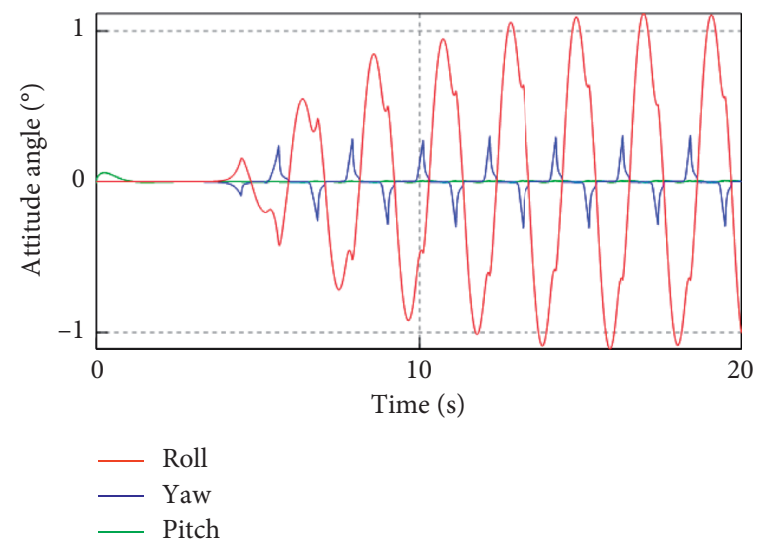

(b)

Figure 17: Changes of the attitude angle under different guide wheel treads: (a) $340 \mathrm{~mm}$ and (b) $540 \mathrm{~mm}$. 


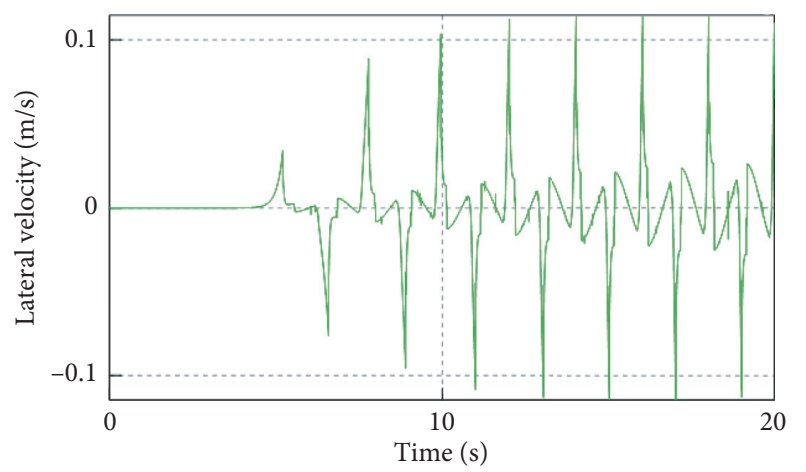

(a)

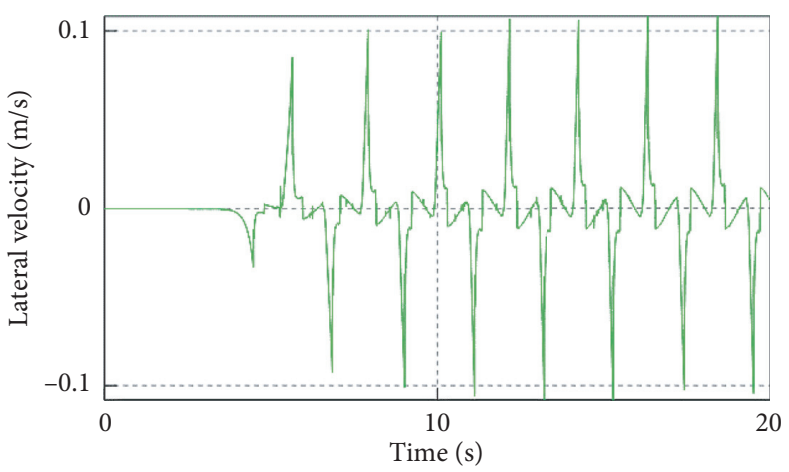

(b)

Figure 18: Changes of the lateral velocity under different guide wheel treads: (a) $340 \mathrm{~mm}$ and (b) $540 \mathrm{~mm}$.

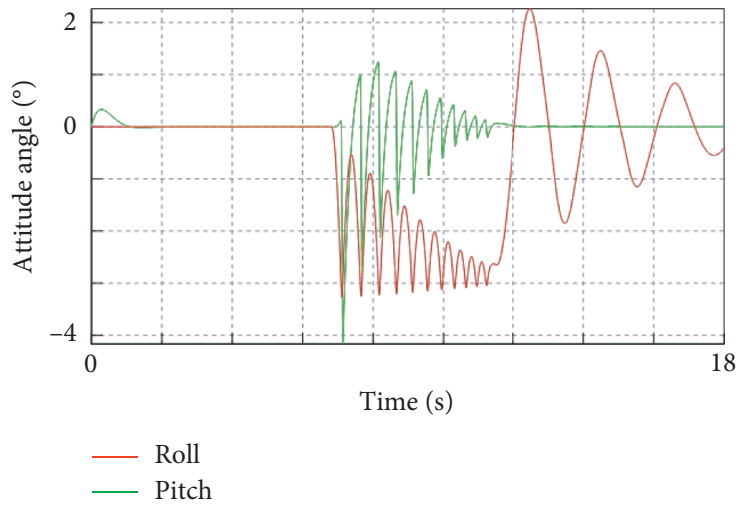

(a)

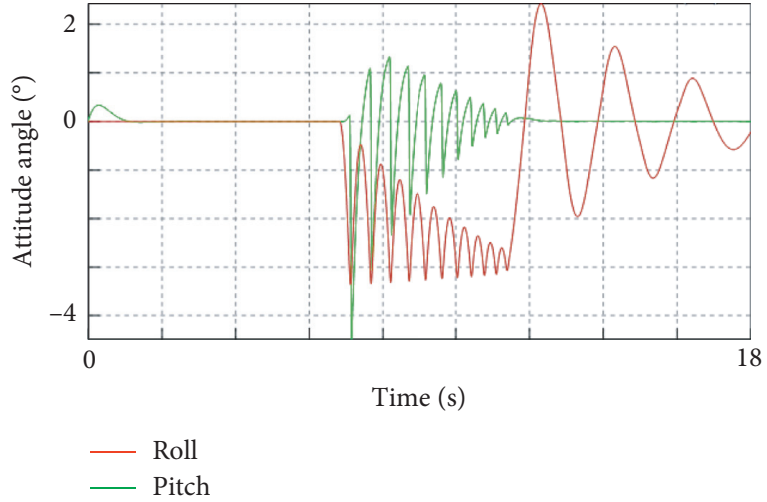

(b)

FIgURE 19: Changes of the attitude angle under different guide wheel treads: (a) $340 \mathrm{~mm}$ and (b) $540 \mathrm{~mm}$.

and the decrease is negligible. Therefore, the guide wheel tread has little influence on vehicle attitude on straight driving.

The changes of the attitude angle of the vehicle on bend driving are shown in Figure 19, and the variations of the amplitude and settling time of the attitude angle with different design parameters of the bogie are shown in Figure 13. The amplitude of the oscillation of the roll angle and the settling time of the first oscillation increase slightly with the increase in the guide wheel tread. The amplitude of the second oscillation of the roll angle is the smallest when the guide wheel tread is $440 \mathrm{~mm}$. The amplitude of the pitch angle's oscillation and the settling time increase slightly with the increase in the guide wheel tread. The pitch angle's settling time remains unchanged when the guide wheel tread is greater than $440 \mathrm{~mm}$.

3.3.5. Influence of the Supporting Wheel Tread. When the center of mass, the driving wheel tread, and the guide wheel tread remain unchanged, the supporting wheel tread gradually increases from $322 \mathrm{~mm}$ to $522 \mathrm{~mm}$ so as to explore the influence of the supporting wheel tread. When the vehicle travels straight, the changes of the attitude angle and lateral velocity are, respectively, shown in Figures 20 and 21. The variations of the amplitude of the roll angle with the design parameters of the bogie are shown in Figure 11. The amplitude of the roll angle decreases rapidly from $1.15^{\circ}$ to $0.60^{\circ}$ with the increase in the supporting wheel tread. According to statistical data, with the increase in the supporting wheel tread, the amplitude of the yaw angle decreases slightly from $0.30^{\circ}$ to $0.29^{\circ}$, and the decrease is negligible. The amplitude of the lateral velocity decreases slightly from $0.110 \mathrm{~m} / \mathrm{s}$ to $0.098 \mathrm{~m} / \mathrm{s}$ with the increase in the driving wheel tread.

The changes of the attitude angle of the vehicle on bend driving are shown in Figure 22, and the variations of the amplitude and settling time of the attitude angle with different design parameters of the bogie are shown in Figure 13. The amplitude and the settling time of the oscillation of the roll angle decrease with the increase in the supporting wheel tread. Except that the decrease in the amplitude of the first oscillation of the roll angle is negligible, all the other three parameters decrease significantly. In addition, the amplitude and the settling time of pitch oscillation decrease significantly with the increase in the supporting wheel tread. 


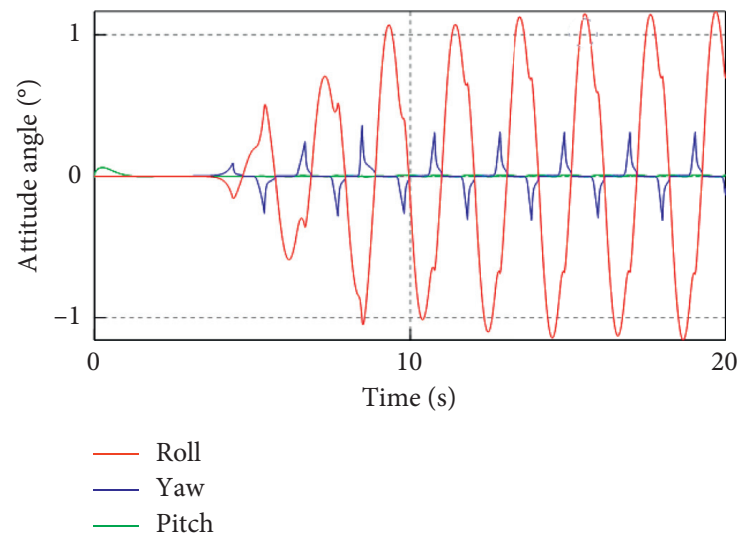

(a)

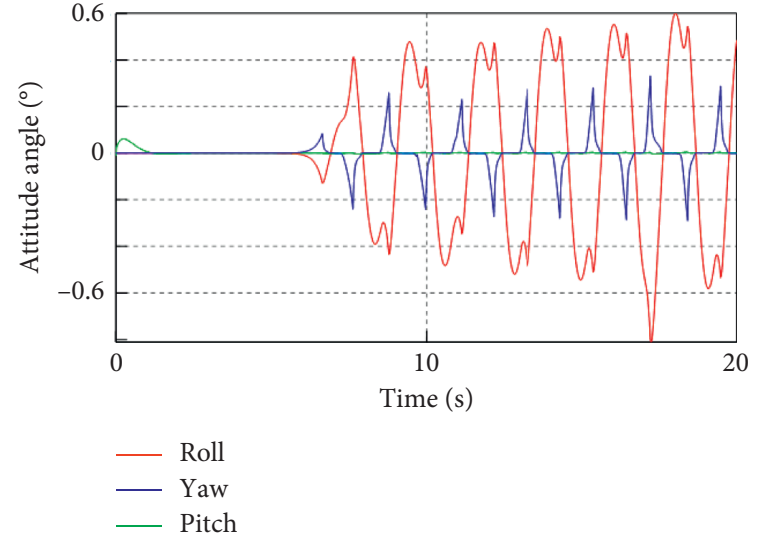

(b)

Figure 20: Changes of the attitude angle under different supporting wheel treads: (a) $322 \mathrm{~mm}$ and (b) $522 \mathrm{~mm}$.

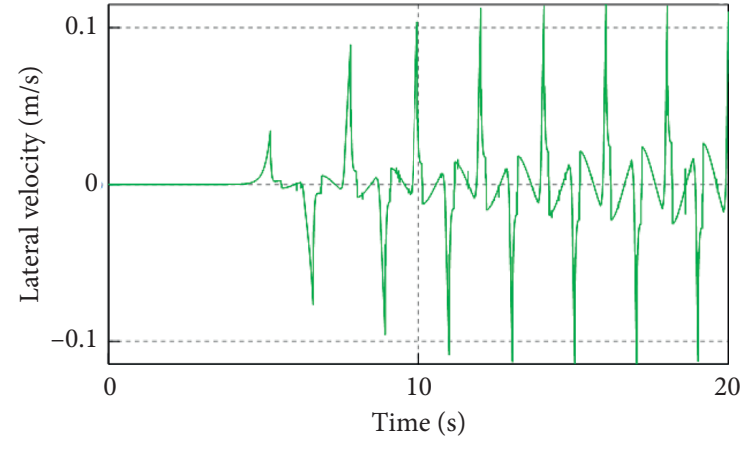

(a)

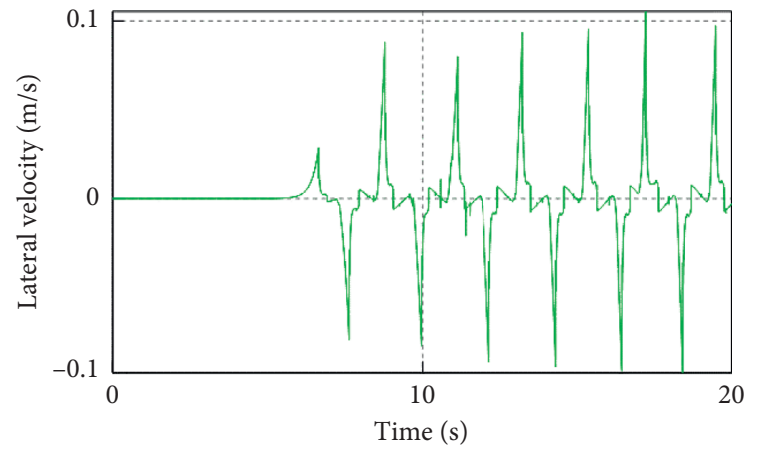

(b)

FIgURE 21: Changes of the lateral velocity under different supporting wheel treads: (a) $322 \mathrm{~mm}$ and (b) $522 \mathrm{~mm}$.

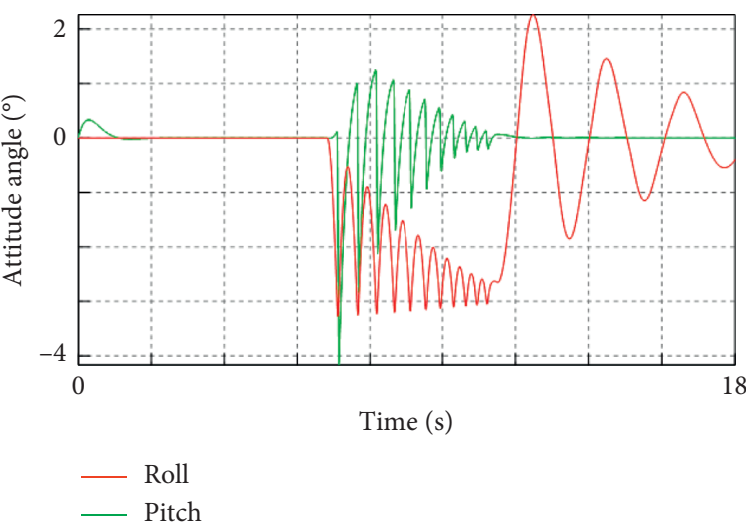

(a)

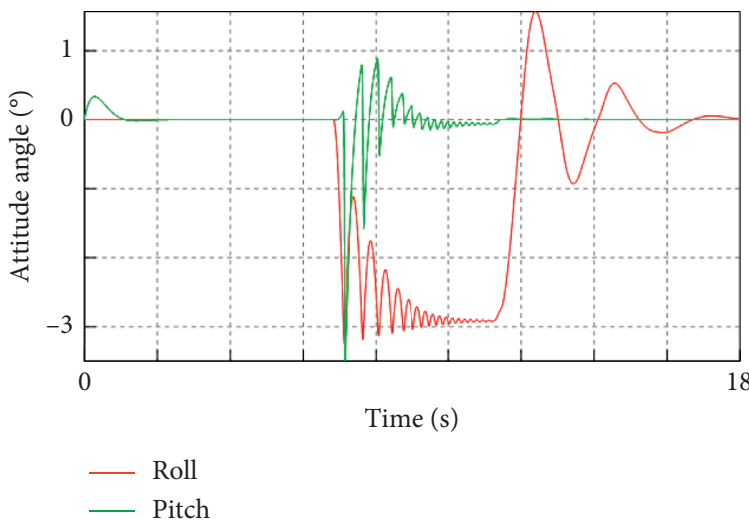

(b)

Figure 22: Changes of the attitude angle under different supporting wheel treads: (a) $322 \mathrm{~mm}$ and (b) $522 \mathrm{~mm}$.

3.4. Optimization Results of the Bogie Design Parameters. According to the simulation trends, the economic and structural feasibility of the system, the correlation among dimensional parameters, and the actual situation of the rail (for example, the widening of the wheel tread is bound to be accompanied by the widening of the rail, which will significantly increase the weight and production cost of the rail) are comprehensively considered for the simulation. Then, with the small amplitude and fast 


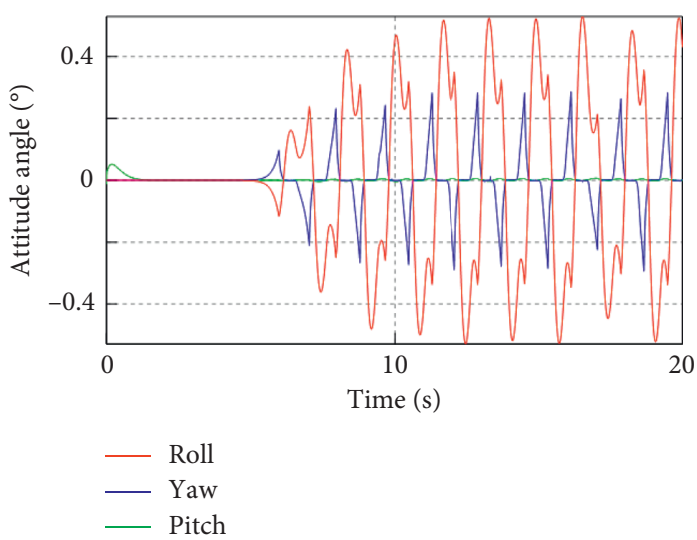

(a)

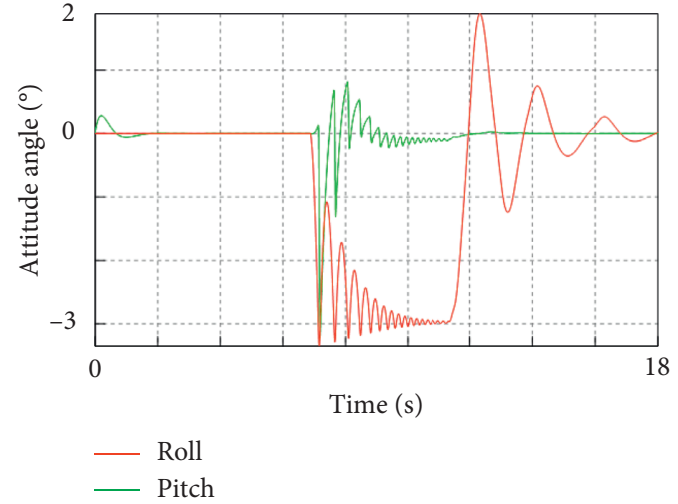

(b)

FIgURE 23: Change of the attitude angle after optimization under different driving conditions: (a) straight line and (b) bend driving.

attenuation of the attitude angle as the optimization objectives, a large number of simulation results are compared and analyzed to obtain the optimal design parameter scheme. The selected design parameters are determined as follows: driving wheel tread of the bogie $(524 \mathrm{~mm})$, distance from the center of mass to the axis of the driving wheel $(1.1 \mathrm{~m})$, the guide wheel tread $(490 \mathrm{~mm})$, and the supporting wheel tread $(472 \mathrm{~mm})$. The changes of the simulated attitude angle are shown in Figure 23. Under the above design parameters, the amplitude of the roll angle of the vehicle on straight driving is $0.55^{\circ}$, which is $52.2 \%$ lower than that before the parameter optimization. Although the amplitude of the first oscillation of the roll angle of the vehicle on bend driving is almost unchanged, the settling time is $2.4 \mathrm{~s}$ after optimal selection, and the decreasing rate reaches $46.7 \%$. The amplitude of the second oscillation of the roll angle is $1.77^{\circ}$, which is $41 \%$ lower than that before the parameter optimization. The settling time of the second oscillation of the roll angle is $4.2 \mathrm{~s}$, which is $36.4 \%$ shorter than that before the parameter optimization. After the optimization, the amplitude of the pitch angle is $3.18^{\circ}$, which is decreased by $23.6 \%$, and the settling time of the pitch angle decreases to $1.1 \mathrm{~s}$, which is decreased by $71.8 \%$. It can be seen that, after the parameter optimization, the vehicle's oscillation characteristics have been significantly improved. The most obvious improvement is the reduction in the settling time of the pitch angle.

\section{Simulation and Analysis of the Suspension- Type Small Rail Vehicle with the Double- Bogie Structure}

After the optimization of the design parameters of the vehicle, the stationarity and safety of the vehicle are improved obviously. Then, the double-bogie structure is introduced to improve the pitch oscillation characteristics during turning. The design parameters of the double-bogie structure are optimized as follows.

4.1. Simulation Model. The simulation model of the doublebogie structure is shown in Figure 24. The structure of the bogie remains unchanged. The parameters before the optimization in Section 3.3.1 are adopted. One carriage is hoisted under the two bogies to improve its driving stationarity.

4.2. Optimization Results of the Design Parameters of the Double-Bogie Vehicle. According to the same analysis method and optimization process as the single-bogie vehicle, the design parameters of bogies with the best performance are determined as follows: the driving wheel tread $(474 \mathrm{~mm})$, the guide wheel tread $(440 \mathrm{~mm})$, the supporting wheel tread $(472 \mathrm{~mm})$, and the distance from the center of mass to the axis of the driving wheel $(1.2 \mathrm{~m})$. The changes of the attitude angle and lateral velocity of the vehicle obtained by simulation are shown in Figure 25. The dotted line in Figure 25(a) represents the amplitude of the roll angle of the vehicle with the single-bogie structure during straight driving after the optimization, and the dotted line in Figure 25(b) represents the amplitude of the pitch angle of the vehicle with the single-bogie structure during turning after the optimization. The dotted line in Figure 25(c) represents the amplitude of the lateral velocity of the vehicle with the single-bogie structure during straight driving after the optimization.

The simulation results are compared with the singlebogie structure vehicle before the optimal selection. After the introduction of the double-bogie structure, the amplitude of the roll angle of the vehicle on straight driving decreases significantly by $71.4 \%$. On bend driving, the settling time of the first oscillation of the roll angle, the amplitude of the pitch angle, and the settling time decrease significantly by $64.4 \%, 66.6 \%$, and $56.4 \%$, respectively.

The simulation results are compared with the optimized single-bogie structure vehicle. After the introduction of the double-bogie structure, under bend driving conditions, the amplitude of the pitch angle decreases significantly by $62.6 \%$. The settling time of the first oscillation decreased significantly by $42.9 \%$. The amplitudes of the roll angle or the lateral velocity are not significantly changed under straight driving conditions.

After the double-bogie structure is adopted and the design parameters are optimized, the overall oscillation 


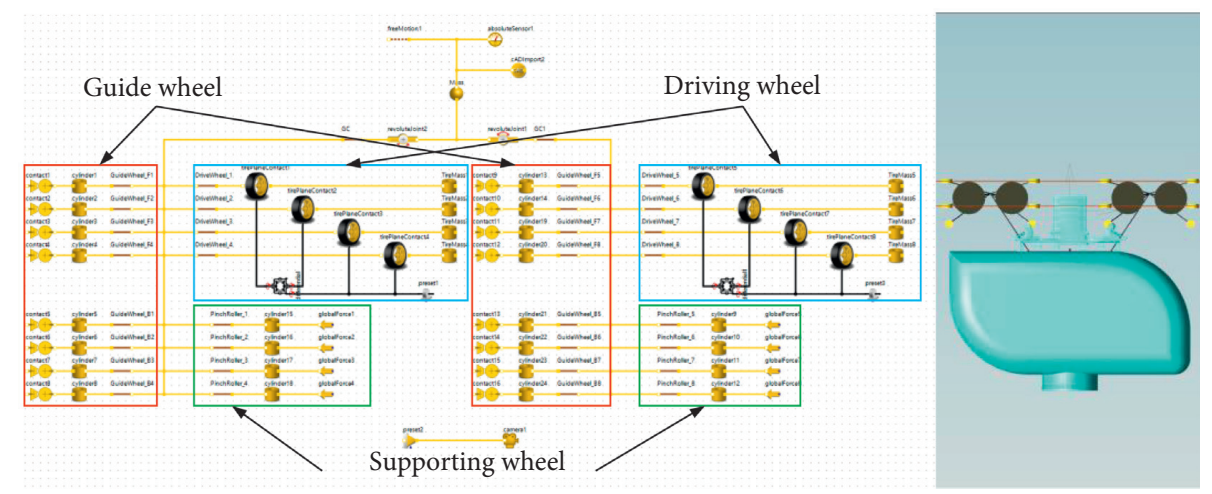

FIgURE 24: Model of the double-bogie vehicle.
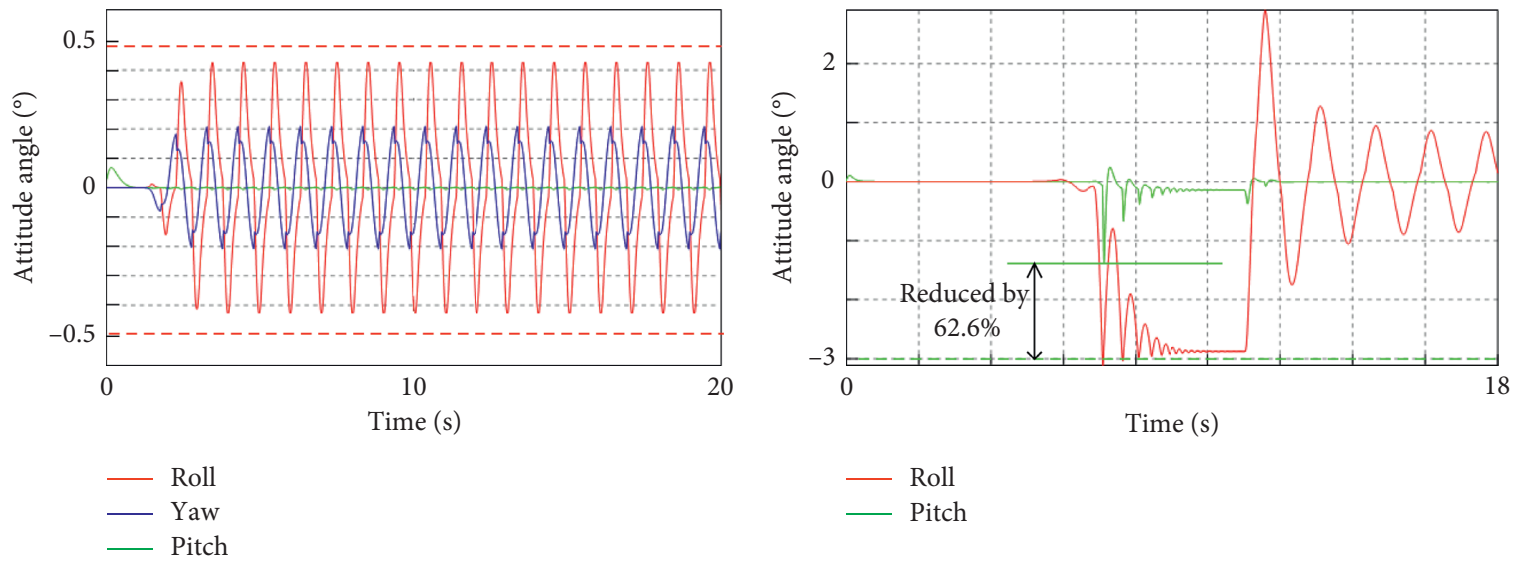

(a)

(b)

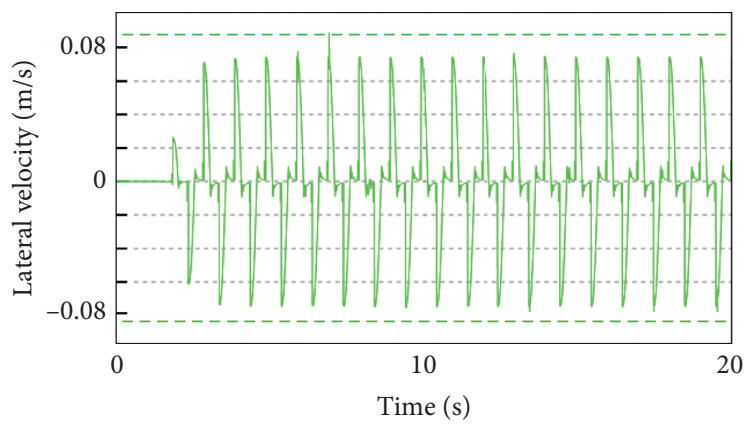

(c)

Figure 25: Simulation results of the double-bogie vehicle. (a) Changes of the attitude angle on straight driving. (b) Changes of the attitude angle on bend driving. (c) Changes of the lateral velocity on straight driving.

characteristics of the vehicle are significantly improved. Moreover, the problem of the excessively large pitch angle of the vehicle under the bend driving conditions is solved.

4.3. Evaluation of Ride Comfort of the Vehicle. The ride comfort requirement of the vehicle is to control the impact of the vibration and shock environment generated by the vehicle on the comfort of passengers within a certain range. Therefore, the ride comfort is mainly evaluated based on the subjective feelings of passengers. According to ISO-2631-1:
1997 (E), the original single-bogie vehicle and the optimized double-bogie vehicle are analyzed and compared. The weighted acceleration RMS is expressed as

$$
a_{w}=\left[\frac{1}{T} \int_{0}^{T} a_{w}^{2}(t) \mathrm{d} t\right]^{(1 / 2)}
$$

Based on the consideration of the vibration of the carriage along $x, y$, and $z$ axes, the total weighted acceleration RMS of the three axes is expressed as 
TABLE 4: Evaluation of ride comfort.

\begin{tabular}{lcc}
\hline Items & Weighted acceleration RMS $\left(\mathrm{m} \cdot \mathrm{s}^{-2}\right)$ & Weighted vibration grade $(\mathrm{dB})$ \\
\hline Original results & 1.7151 & 124.6858 \\
Optimized results & 0.9219 & 119.2937 \\
\hline
\end{tabular}

Table 5: Parameters of the test vehicle.

\begin{tabular}{lccc}
\hline $\begin{array}{l}\text { Supporting wheel tread } \\
(\mathrm{mm})\end{array}$ & $\begin{array}{c}\text { Driving wheel tread } \\
(\mathrm{mm})\end{array}$ & $\begin{array}{c}\text { Guide wheel tread } \\
(\mathrm{mm})\end{array}$ & $\begin{array}{c}\text { The distance between the center of mass and the axis of the } \\
\text { wheel }(\mathrm{m})\end{array}$ \\
\hline 340 & 374 & 322 & 1.5
\end{tabular}

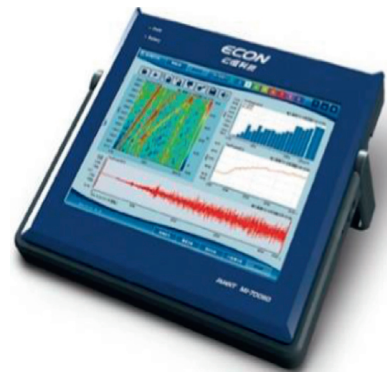

(a)

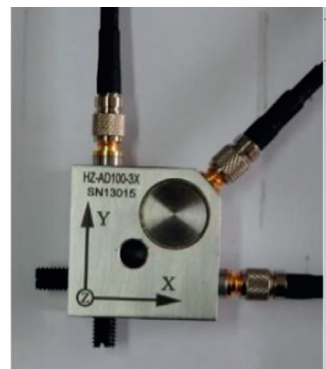

Figure 26: Measurement system. (a) Acquisition system. (b) Sensor position.

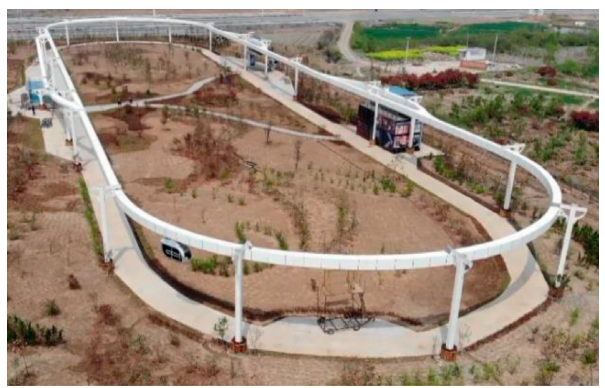

FIGURE 27: Test equipment.

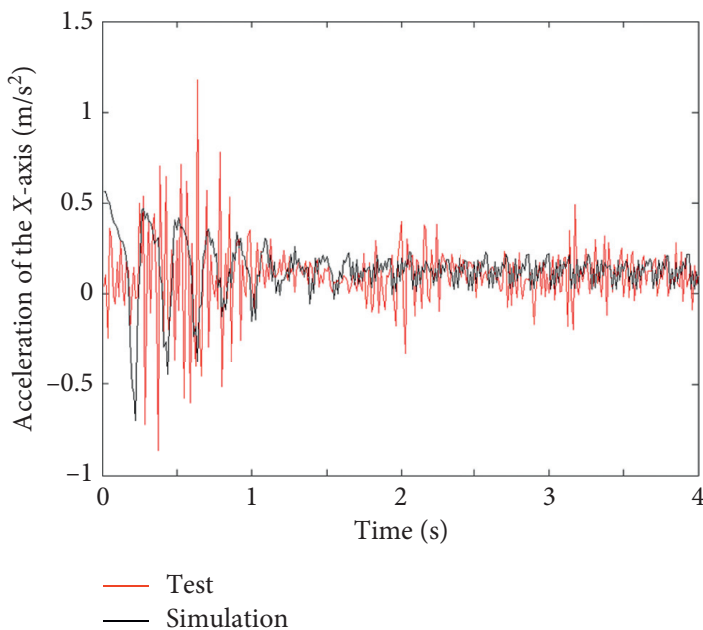

(a)

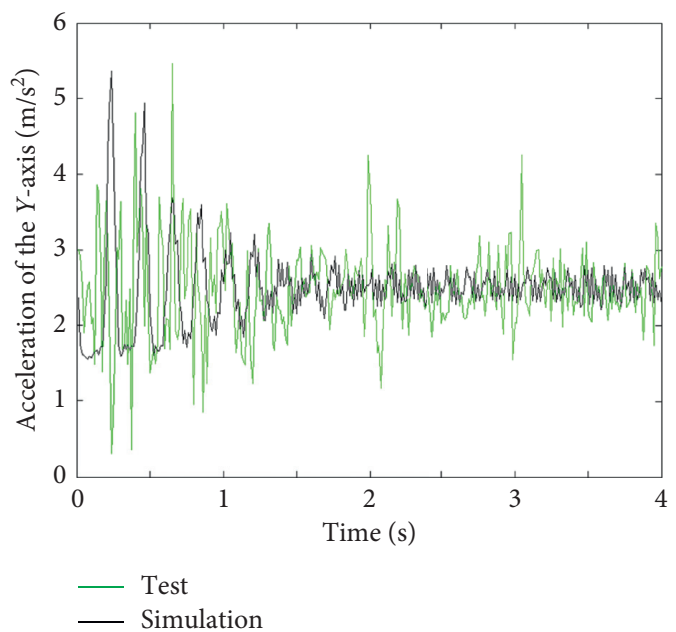

(b)

FIgURE 28: Continued. 


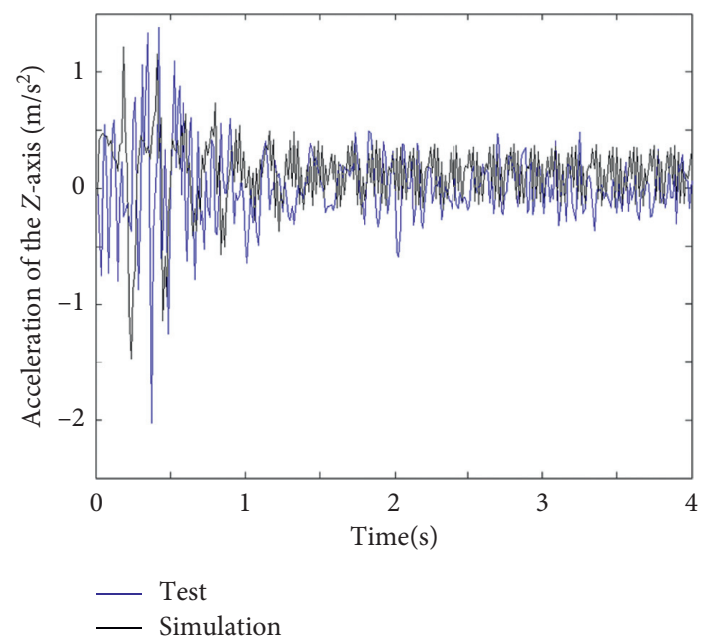

(c)

Figure 28: Comparison of experimental acceleration and simulation acceleration in different axes: (a) $X$-axis, (b) $Y$-axis, and (c) $Z$-axis.

TABle 6: Analysis and comparison of experimental acceleration and simulation acceleration.

\begin{tabular}{|c|c|c|c|c|}
\hline Directions & Conditions & $\begin{array}{l}\text { Simulation results } \\
\left(\mathrm{m} / \mathrm{s}^{2}\right)\end{array}$ & $\begin{array}{c}\text { Experimental results } \\
\left(\mathrm{m} / \mathrm{s}^{2}\right)\end{array}$ & Errors (\%) \\
\hline \multirow{2}{*}{$\begin{array}{l}\text { Average absolute value of accelerations of the } \\
X \text {-axis }\end{array}$} & Before stabilization & 0.27 & 0.29 & 6.90 \\
\hline & After stabilization & 0.13 & 0.12 & 7.69 \\
\hline \multirow{2}{*}{$\begin{array}{l}\text { Average absolute value of accelerations of the } \\
Y \text {-axis }\end{array}$} & Before stabilization & 2.42 & 2.52 & 3.97 \\
\hline & After stabilization & 2.51 & 2.50 & 0.40 \\
\hline \multirow{2}{*}{$\begin{array}{l}\text { Average absolute value of accelerations of the } \\
Z \text {-axis }\end{array}$} & Before stabilization & 0.40 & 0.43 & 6.98 \\
\hline & After stabilization & 0.19 & 0.15 & 21.05 \\
\hline
\end{tabular}

TABLE 7: Analysis and comparison of experimental frequencies and simulation frequencies.

\begin{tabular}{lccc}
\hline Directions & Orders & Simulation results $(\mathrm{Hz})$ & Experimental results $(\mathrm{Hz})$ \\
\hline & 1 & 2.03 & 2.42 \\
Frequencies of the $X$-axis & 2 & 3.50 & 3.75 \\
& 3 & 5.02 & 5.08 \\
\hline \multirow{2}{*}{ Frequencies of the $Y$-axis } & 1 & 0.61 & 1.08 \\
& 2 & 1.72 & 1.92 \\
\hline & 3 & 3.44 & 3.42 \\
Frequencies of the $Z$-axis & 1 & 3.73 & 3.67 \\
& 2 & 5.72 & 5.75 \\
\hline
\end{tabular}

$$
a_{v}=\left[\left(1.4 a_{x w}\right)^{2}+\left(1.4 a_{y w}\right)^{2}+a_{z w}^{2}\right]^{(1 / 2)} .
$$

The relationship between the weighted vibration grade and the weighted acceleration RMS is expressed as

$$
L_{a w}=201 g\left(\frac{a_{w}}{a_{0}}\right) .
$$

The weighted acceleration RMS and the weighted vibration grade before and after the optimization are shown in Table 4 .

\section{Experimental Verification}

After the optimization, the assembly work of the doublebogie vehicle is still underway. Due to the change of the wheel tread, the laborious adjustment of the rail is required. The double-bogie vehicle before the optimization has already met the testing conditions. In this section, in order to experimentally verify the simulation model, the simulation results of the double-bogie vehicle before the optimization (intermediate state) can be compared with the experimental results obtained from the actual vehicle. The MI-7008D 
portable data acquisition analyzer and two three-axis accelerometers were used to measure the acceleration [24, 28]. The parameters of the double-bogie vehicle before the optimization are given in Table 5. Test equipment shown in Figure 26(a) was fixed in the carriage shown in Figure 26(b). The vehicle travels on the rail, as shown in Figure 27. The turning radius of the rail is $20 \mathrm{~m}$. The sampling frequency of the three-axis accelerometer is set at $640 \mathrm{~Hz}$ to record and analyze the acceleration data of the vehicle.

The comparison results of experimental acceleration and simulation acceleration in a selected test interval are shown in Figure 28. The experimental and simulation results of acceleration and partial frequencies are provided in Tables 6 and 7 , respectively. The experimental results were basically consistent with the acceleration and frequencies obtained from the simulation. The difference in the $X$-direction was mainly caused by the unstable speed control of the experimental vehicle and the impact of vehicle turning. The difference in the $Y$-direction was mainly caused by the change in the force applied on the steering arm during the steering process, the contact between the guide wheel and the side rail, and the influence of crosswind. The difference in the $Z$-direction was mainly caused by the roughness of the experimental road.

\section{Conclusion}

In this paper, a novel suspension-type small rail system combining the advantages of rail vehicles and automobiles was studied. Through the theoretical analysis, multibody dynamics simulation, and experiments, the driving attitude and oscillation characteristics of the vehicle were studied in order to improve the driving stationarity and ride comfort of the vehicle.

(1) The dynamic theoretical model of the suspensiontype small rail vehicle is established to lay the theoretical foundation for the subsequent study. The structural parameters influencing the vehicle driving stationarity are obtained for the purpose of guiding the further analysis and optimization.

(2) The multibody dynamics simulation model of the novel structure is established to analyze the attitude angle of the suspension-type small rail vehicle with single bogie and double bogies. With the small amplitude and fast attenuation of the attitude angle and lateral velocity during straight driving and bend driving as the optimization objectives, key design parameters are optimized, including the introduction of the supporting wheel, supporting wheel tread, driving wheel tread, guide wheel tread, and center of mass. The supporting wheel has a great influence on the driving attitude of the vehicle, and the introduction of the supporting wheel in the structure can effectively suppress vehicle swing. The change of carriage's center of mass has a great influence on the driving stationarity of the vehicle. The closer the center of mass is to the track surface, the more stable the vehicle driving is. When the vehicle is driving in a straight line, the driving wheel tread and supporting wheel tread have a great influence on the roll angle. The larger the wheel tread is, the more stable the driving is. The guide wheel tread has less influence on the roll angle. During bend driving, the wheel treads of driving wheels and supporting wheels have a great influence on the roll angle and pitch angle, whereas the wheel tread of the guide wheel has little influence.

(3) The wheel treads of the driving wheels and supporting wheels are closely related to the width of the track, and widening the track necessarily increases the operation cost. Therefore, both feasibility and economy of the scheme should be considered comprehensively in the optimization process, and the reasonable scheme of the bogie structure should be selected optimally. Compared with the singlebogie structure, the optimized double-bogie structure is greatly improved in terms of settling time and amplitudes of the roll angle and pitch angle. According to ISO-2631, the original single-bogie vehicle leads to the uncomfortable state of passengers, whereas the ride comfort of the optimized double-bogie vehicle has been effectively improved.

(4) The simulation acceleration values in three directions at the same position of the vehicle are compared with those measured in the test site. The curve variation trend was basically the same as that of simulation results. Due to the influences of track plane flatness and environmental factors, the amplitudes in the test were slightly different. The simulation model and optimization results are experimentally verified. The study can greatly improve the ride comfort. Therefore, this study has great theoretical and engineering values.

\section{Data Availability}

The data used to support the findings of this study are available from the corresponding author upon request.

\section{Conflicts of Interest}

The authors declare that there are no conflicts of interest regarding the publication of this article.

\section{Acknowledgments}

This research was supported by Jiangsu Tianle Intelligent Technology Co., Ltd. and the National Natural Science Foundation of China (Grant no. 51905010).

\section{References}

[1] A. Nugmanova, W. H. Arndt, M. A. Hossain, and J. R. Kim, "Effectiveness of ring roads in reducing traffic congestion in cities for long run: big almaty ring road case study," Sustainability, vol. 11, no. 18, 2019.

[2] S. Tahmasseby and L. Kattan, "Preliminary economic appraisal of personal rapid transit (PRT) and urban gondola feeder systems serving a university campus and its 
surrounding major attractions," Canadian Journal of Civil Engineering, vol. 42, no. 1, pp. 67-79, 2015.

[3] M. M. Minderhoud and H. J. Van Zuylen, "Preliminary assessment of the operation of a personal rapid transit system in eindhoven," 2002.

[4] D. Fichter, Analysis of Dual-Mode Transport, Highway Research Record, Washington, DC, USA, 1971.

[5] D. Fichter, "Personal rapid transit: what's in a name?" Futurist, vol. 25, no. 3, 1991.

[6] C. Bernasconi, M. R. Strager, V. Maskey, and M. Hasenmyer, "Assessing public preferences for design and environmental attributes of an urban automated transportation system," Landscape and Urban Planning, vol. 90, no. 3, pp. 155-167, 2009.

[7] T. Kerr, M. Lowson, and A. Smith, "Heathrow airport's personal rapid transit system proves to be a viable transport solution," Proceedings of the Institution of Civil Engineers-Civil Engineering, vol. 167, no. 2, pp. 66-73, 2014.

[8] J. Landers, "Personal rapid transit system begins test runs at heathrow airport," Civil Engineering, vol. 80, no. 12, pp. 24-25, 2010.

[9] D. N. Jiang, Y. Huang, D. H. Hao, and T. Zhang, "Active damping of drive train oscillations for BAS hybrid vehicle considering multi-operations," in Proceedings of the 35th Chinese Control Conference, J. Chen and Q. Zhao, Eds., pp. 8824-8829pp. 8824-, Chengdu, China, 2016.

[10] C. Cai, Q. He, S. Zhu, W. Zhai, and M. Wang, "Dynamic interaction of suspension-type monorail vehicle and bridge: numerical simulation and experiment," Mechanical Systems and Signal Processing, vol. 118, pp. 388-407, 2019.

[11] Y. Bao, Y. Li, and J. Ding, "A case study of dynamic response analysis and safety assessment for a suspended monorail system," International Journal of Environmental Research and Public Health, vol. 13, no. 11, 2016.

[12] M. Kozłowski, W. Choromański, and J. Kowara, "Analysis of dynamic properties of the PRT vehicle-track system," Bulletin of the Polish Academy of Sciences Technical Sciences, vol. 63, no. 3, pp. 799-806, 2015.

[13] Y. Jiang, P. Wu, J. Zeng, Y. Zhang, Y. Zhang, and S. Wang, "Multi-parameter and multi-objective optimisation of articulated monorail vehicle system dynamics using genetic algorithm," Vehicle System Dynamics, vol. 58, no. 1, pp. 74-91, 2019.

[14] Q. He, C. Cai, S. Zhu, K. Wang, and W. Zhai, “An improved dynamic model of suspended monorail train-bridge system considering a tyre model with patch contact," Mechanical Systems and Signal Processing, vol. 144, 2020.

[15] Q. Gao, K. Cui, Z. Li, and Y. Li, "Numerical investigation of the dynamic performance and riding comfort of a straddletype monorail subjected to moving trains," Applied Sciences, vol. 10, no. 15, 2020.

[16] Z. Junchao, D. Zixue, and Y. Zeng, "Dynamic response of the full-scale straddle-type monorail vehicles with single-axle bogies," Mechanics, vol. 25, no. 1, 2019.

[17] J. Zhou, Z. Du, Z. Yang, and Z. Xu, "Dynamics study of straddle-type monorail vehicle with single-axle bogies-based full-scale rigid-flexible coupling dynamic model," IEEE Access, vol. 7, pp. 110249-110257, 2019.

[18] H. Gou, W. Zhou, C. Yang, Y. Bao, and Q. Pu, "Dynamic response of a long-span concrete-filled steel tube tied arch bridge and the riding comfort of monorail trains," Applied Sciences, vol. 8, no. 4, 2018.

[19] H. Wang and E. Zhu, "Dynamic response analysis of monorail steel-concrete composite beam-train interaction system considering slip effect," Engineering Structures, vol. 160, pp. 257-269, 2018.

[20] M. Naeimi, M. Tatari, A. Esmaeilzadeh, and M. Mehrali, "Dynamic interaction of the monorail-bridge system using a combined finite element multibody-based model," Proceedings of the Institution of Mechanical Engineers, Part K: Journal of Multi-body Dynamics, vol. 229, no. 2, pp. 132-151, 2014.

[21] C. H. Lee, C. W. Kim, M. Kawatani, N. Nishimura, and T. Kamizono, "Dynamic response analysis of monorail bridges under moving trains and riding comfort of trains," Engineering Structures, vol. 27, no. 14, pp. 1999-2013, 2005.

[22] P. T. Nguyen, T. D. Pham, and H. P. Hoang, "A nonlinear dynamic foundation model for dynamic response of tracktrain interaction," Shock and Vibration, vol. 2020, Article ID 5347082, 10 pages, 2020.

[23] I. Kowarska, J. Korta, K. Kuczek, and T. Uhl, "Fully equipped dynamic model of a bus," Shock and Vibration, vol. 2014, Article ID 201952, 9 pages, 2014.

[24] R. Yuan-Yuan, Z. Hong-Wei, L. Xian-Sheng, and Z. Xue-Lian, "Study on vehicle track model in road curved section based on vehicle dynamic characteristics," Mathematical Problems in Engineering, vol. 2012, Article ID 818136, 17 pages, 2012.

[25] S. Zhao, D. Wang, J. Sun, and H. Liu, "Optimization model for multi-vehicle-type structure in urban bus systems," Mathematical Problems in Engineering, vol. 2017, Article ID 7914318, 6 pages, 2017.

[26] L. Zhao and Z. Liu, "Vehicle velocity and roll angle estimation with road and friction adaptation for four-wheel independent drive electric vehicle," Mathematical Problems in Engineering, vol. 2014, Article ID 801628, 11 pages, 2014.

[27] T. Ni, W. H. Li, H. Y. Zhang, H. J. Yang, and Z. F. Kong, "Pose prediction of autonomous full tracked vehicle based on 3D sensor," Sensors, vol. 19, no. 23, 2019.

[28] K. Lv, K. Wang, Z. Chen, C. Cai, and L. Guo, "Influence of wheel eccentricity on vertical vibration of suspended monorail vehicle: experiment and simulation," Shock and Vibration, vol. 201710 pages, Article ID 1367683, 2017. 